\title{
Matrix Metalloproteinase-3 Promotes Early Blood-Spinal Cord Barrier Disruption and Hemorrhage and Impairs Long-Term Neurological Recovery after Spinal Cord Injury
}

\author{
Jee Youn Lee, ${ }^{{ }^{\dagger}}$ Hae Young Choi, ${ }^{\dagger \dagger}$ Hyun-Jong Ahn, ${ }^{\ddagger}$ Bong Gun Ju,,${ }^{\S}$ and Tae Young Yune ${ }^{* \dagger 币}$
}

\begin{abstract}
From the Age-Related and Brain Diseases Research Center,$*$ the Neurodegeneration Control Research Center, ${ }^{\dagger}$ and the Departments of Microbiology ${ }^{\ddagger}$ and Biochemistry and Molecular Biology, "School of Medicine, Kyung Hee University, Seoul; and the Department of Life Science, ${ }^{\S}$ Sogang University, Seoul, Republic of Korea
\end{abstract}

\begin{abstract}
CME Accreditation Statement: This activity ("ASIP 2014 AJP CME Program in Pathogenesis") has been planned and implemented in accordance with the Essential Areas and policies of the Accreditation Council for Continuing Medical Education (ACCME) through the joint sponsorship of the American Society for Clinical Pathology (ASCP) and the American Society for Investigative Pathology (ASIP). ASCP is accredited by the ACCME to provide continuing medical education for physicians.
\end{abstract}

The ASCP designates this journal-based CME activity (“ASIP 2014 AJP CME Program in Pathogenesis”) for a maximum of 48 AMA PRA Category 1 Credit(s) ${ }^{\mathrm{TM}}$. Physicians should only claim credit commensurate with the extent of their participation in the activity.

CME Disclosures: The authors of this article and the planning committee members and staff have no relevant financial relationships with commercial interests to disclose.

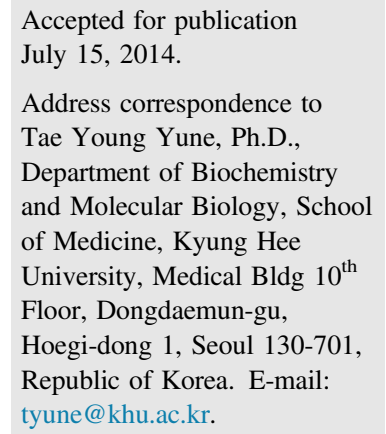

\begin{abstract}
After spinal cord injury (SCI), blood-spinal cord barrier (BSCB) disruption by matrix metalloproteinases (MMPs) leads to BSCB permeability and blood cell infiltration, contributing to permanent neurological disability. Herein, we report that MMP-3 plays a critical role in BSCB disruption after SCI in mice. MMP-3 was induced in infiltrated neutrophils and blood vessels after SCI, and NF- $\kappa B$ as a transcription factor was involved in MMP-3 expression. BSCB permeability and blood cell infiltration after injury were more reduced in Mmp3 knockout (KO) mice than in wild-type (WT) mice, which was significantly inhibited by Mmp3 siRNA or a general inhibitor of MMPs, N-isobutyl-N-(4-methoxyphenylsulfonyl)glycyl hydroxamic acid. The level of tight junction proteins, such as occludin and zonula occludens-1, which decreased after SCI, was also higher in Mmp3 K0 than in WT mice. Exogenously, MMP-3 injection into the normal spinal cord also induced BSCB permeability. Furthermore, MMP-9 activation after injury was mediated by MMP-3 activation. Finally, improved functional recovery was observed in $\mathrm{Mmp} 3 \mathrm{KO}$ mice compared with WT mice after injury. These results demonstrated the role of MMP-3 in BSCB disruption after SCI for the first time and suggest that the regulation of MMP-3 can be considered a therapeutic target to inhibit BSCB disruption and hemorrhage, and thereby enhance functional recovery after acute SCI. (Am J Pathol 2014, 184: 2985-3000; http://dx.doi.org/10.1016/j.ajpath.2014.07.016)
\end{abstract}

Traumatic spinal cord injury (SCI) is a devastating condition that results in permanent disability. Currently, treatment options are limited, but significant advances have been made in understanding the pathophysiological features of SCI. Initial mechanical injury, followed by secondary injury, is known to contribute to pathophysiological features, leading to cell death and functional disability after SCI. ${ }^{1}$

The blood-spinal cord barrier (BSCB) is the functional equivalent of the blood-brain barrier (BBB), providing a specialized microenvironment for the cellular constituents of the spinal cord. The barrier function of BSCB is based on the specialized system of nonfenestrated endothelial cells and their accessory structures, including basement membrane, pericytes, and astrocytic end feet processes, which provide its regulatory and protective functions. ${ }^{2}$ When BSCB is damaged by injury,

\footnotetext{
Supported by the Pioneer Research Center Program through the National Research Foundation of Korea, funded by the Ministry of Science, Information and Communications Technology and Future Planning grant 2010-0019349 (T.Y.Y.), and a Korea Health Technology R\&D Project grant through the Korea Health Industry Development Institute, funded by the Ministry of Health and Welfare, Republic of Korea, grant HI13C14600000 (T.Y.Y.).

Disclosures: None declared.
} 
blood cells cross into injured parenchyma and contribute to secondary injuries, such as inflammation. ${ }^{3-5}$ These secondary damages induce apoptosis of neurons and glia, leading to permanent neurological deficits. ${ }^{6}$

Matrix metalloproteinases (MMPs) are known to degrade extracellular matrix and other extracellular proteins ${ }^{7}$ and are essential for remodeling of extracellular matrix and wound healing. ${ }^{8}$ However, excessive proteolytic activity of MMPs can be detrimental, leading to numerous pathological conditions, including BBB/BSCB disruption after injury. ${ }^{6,-12}$ For example, MMP-9 plays a key role in abnormal vascular permeability after SCI, and blocking of MMP-9 improves functional recovery. ${ }^{6}$ After SCI, MMP-12 up-regulation increases BSCB permeability, followed by blood cell infiltration, thereby hindering recovery of motor function. ${ }^{13}$ After brain focal ischemia, the degradation of tight junction (TJ) proteins is also blocked by inhibiting MMP-2 and MMP-9 activities. $^{14}$

Several studies suggest that MMP-3 is involved in BBB disruption after injury. For example, lipopolysaccharide (LPS)-induced BBB disruption is reduced in $\mathrm{Mmp} 3$ knockout (KO) mice when compared with wild-type (WT) mice. ${ }^{11}$ In addition, cyclooxygenase- 1 and cyclooxygenase2 modulate LPS-induced BBB disruption through MMP-3 and MMP-9. ${ }^{15}$ Recently, BBB disruption in a MPTP mouse model of Parkinson's disease is suppressed by MMP-3 deletion. ${ }^{16}$ However, no direct evidence for the role of MMP-3 in the BBB/BSCB disruption after accidental trauma, such as SCI and/or ischemic stroke, has been presented yet. Thus, we examined the precise role of MMP-3 in BSCB disruption after SCI through four different approaches: i) Mmp3 KO mice, ii) $M m p 3$ siRNA, iii) a general inhibitor of MMPs, and iv) exogenous MMP-3 injection. Finally, we determined the effect of MMP-3 on functional recovery and histological outcome after SCI by comparing Mmp3 KO mice with WT control.

\section{Materials and Methods}

\section{Animals and SCI}

We used adult (13- to 16-week-old, 28 to $30 \mathrm{~g}$ ) male WT $(n=171), M m p 3 \mathrm{KO}(n=60)$, and $I k k \beta^{\text {4mye }}(n=21)$ mice in this study. Mmp3 KO mice were generously donated by Dr. Tong Hyup Joh (Cornell University, Ithaca, NY). Myeloid cell type-specific IкB kinase (Ikk)- $\beta$-deficient $\left(I k k \beta^{\Delta m y e}\right)$ mice were donated by Dr. Sung Joong Lee (Seoul University, Seoul, Republic of Korea). Because the genetic background of these mice has been maintained in C57BL/6, the same strain from Samtako (Osan, Republic of Korea) was used as WT. Adult male mice (18 to $22 \mathrm{~g}$; Samtako) were anesthetized with $4 \%$ chloral hydrate, and a laminectomy was performed at the T9 to T10 level, exposing the cord beneath without disrupting the dura. The exposed dorsal surface of the cord then was subjected to moderate contusion injury (50 kilodyne force per 500- to $600-\mu \mathrm{m}$ displacement) using the Infinite Horizons impactor (Infinite Horizons Inc., Lexington, KY). For sham-operated on controls, animals underwent a T9 to T10 laminectomy without contusion injury. Surgical interventions and postoperative animal care were performed in accordance with the Guidelines and Policies for Rodent Survival Surgery provided by the Animal Care Committee of the Kyung Hee University (Seoul, Republic of Korea).

\section{Drug Administration}

Mouse Mmp3 siRNA and control nontargeting siRNA (control siRNA) were purchased from Thermo Fisher Scientific (Lafayette, CO). Each targeted siRNA was a mixture of four siRNAs formulated to enhance the effectiveness of the mixture in knocking down the target gene. The control siRNA was a mixture of siRNAs with scrambled sequences, confirmed by microarray to have minimal targeting of known genes in human, mouse, and rat cells. siRNAs were dissolved in distilled water ( $\mathrm{pH} 7.4)$ and injected bilaterally ( $2 \mu \mathrm{L}$ per site; final, 0.01 or $0.05 \mathrm{nmol}$ per cord) into the spinal cord at 30 minutes after SCI, as previously reported. ${ }^{17}$ An active MMP-3 recombinant enzyme (Calbiochem, La Jolla, CA) was dissolved in phosphate-buffered saline (PBS) and then injected bilaterally ( $5 \mu \mathrm{L}$ per site; final, 20 or 200 pmol per cord) in normal spinal cord. Bilateral intraspinal injection was performed at the T9 to T10 level, according to the following stereotaxic coordinate: lateral $\pm 0.3 \mathrm{~mm}, 0.5-\mathrm{mm}$ depth. Control groups received injections of equal volumes of control siRNA or PBS. A general inhibitor of MMPs, N-isobutyl-N(4-methoxyphenylsulfonyl)glycyl hydroxamic acid (NNGH; Enzo Life Sciences International, Plymouth Meeting, PA) was dissolved in $10 \%$ dimethyl sulfoxide (5 $\mu \mathrm{L}$ of $5 \mathrm{mmol} / \mathrm{L} \mathrm{NNGH}$ ) and administrated by intraspinal injection (lesion center, $0.5-\mathrm{mm}$ depth) using glass pipette at 30 minutes after SCI, as previously described. ${ }^{18}$ Intraspinal injection into the spinal cord was performed using a pulled glass capillary pipette (30- $\mu \mathrm{m}$ external tip diameter), as previously described. ${ }^{19}$

\section{Tissue Preparation}

Tissue preparation was performed as previously described ${ }^{20}$ At specific time points after SCI, animals were anesthetized with chloral hydrate $(500 \mathrm{mg} / \mathrm{kg})$ and perfused via cardiac puncture initially with $0.1 \mathrm{~mol} / \mathrm{L} \mathrm{PBS}$, $\mathrm{pH} 7.4$, and subsequently with $4 \%$ paraformaldehyde in $0.1 \mathrm{~mol} / \mathrm{L} \mathrm{PBS}, \mathrm{pH}$ 7.4. A $20-\mathrm{mm}$ section of the spinal cord, centered at the lesion site, was dissected out, post-fixed by immersion in the same fixative for 4 hours, and placed in $30 \%$ sucrose in $0.1 \mathrm{~mol} / \mathrm{L}$ PBS, $\mathrm{pH}$ 7.4. The segment was embedded in optimal cutting temperature compound for frozen sections, and longitudinal or transverse sections were then cut at 10 or $20 \mu \mathrm{m}$. For molecular and biochemical works, animals were perfused with $0.1 \mathrm{~mol} / \mathrm{L}$ PBS, and segments of spinal cord $(8 \mathrm{~mm})$, including the lesion site, were isolated and frozen at $-80^{\circ} \mathrm{C}$. 


\section{IHC Data}

Frozen sections were processed for immunohistochemistry (IHC) with antibodies against MMP-3 (Santa Cruz Biotechnology, Santa Cruz, CA), ED-1 (Serotec, Raleigh, NC), CD11b (Serotec), NeuN (Millipore, Billerica, MA), CC1 (Oncogene, Cambridge, MA), glial fibrillary acidic protein (GFAP; Millipore), myeloperoxidase (MPO; Neomarkers, Fremont, CA), CD31 (BD Biosciences, San Jose, CA), NF-кB (Santa Cruz Biotechnology), occludin (Invitrogen, Carlsbad, CA), claudin-5 (Abcam, Cambridge, MA), zonula occludens (ZO-1; Invitrogen), and neurofilament $200 \mathrm{kDa}$ (NF200; Sigma, St. Louis, MO), as previously described. ${ }^{21}$ The sections were incubated with primary antibodies, followed by biotin-conjugated secondary antibodies (Dako, Carpinteria, CA). The avidin-biotin complex method was used to detect labeled cells using a Vectastain kit (Vector Labs, Burlingame, CA). Diaminobenzidene served as the substrate for peroxidase. For double labeling, fluorescein isothiocyanate (FITC) or cy3-conjugated secondary antibodies (Jackson ImmunoResearch, West Grove, PA) were used. Also, nuclei were labeled with DAPI, according to the manufacturer's protocol (Molecular Probes, Eugene, OR). In all controls, reaction to the substrate was absent if the primary antibody was omitted or if the primary antibody was replaced by a nonimmune, control antibody. Serial sections were also stained for histological analysis with Cresyl violet acetate.

\section{RNA Isolation and Real-Time RT-PCR}

Total RNA was isolated from spinal cord segments $(8 \mathrm{~mm})$, centered at the lesion site by using TRIzol reagent (Invitrogen), according to the manufacturer's instruction. cDNA was synthesized from $5 \mu \mathrm{g}$ of the total RNA using MMLVRT (Invitrogen), and real-time PCR was performed using SYBR Green PCR master mix (Invitrogen), as previously described. ${ }^{22}$ The primers used for real-time PCR were synthesized by Genotech (Daejeon, Republic of Korea), and the sequences of the primers are as follows $\left(5^{\prime}\right.$ to $\left.3^{\prime}\right)$ : MMP-3, 5'-GGCTTCAGTACCTTCCCAGG-3' (forward) and $5^{\prime}$-GCAGCAACCAGGAATAGGTT- $3^{\prime}$ (reverse); MMP-12, 5'-GAAACCCCCATCCTTGACAA-3' (forward) and 5' ${ }^{\prime}$-TTCCACCAGAAGAACCAGTCTTTAA- ${ }^{\prime}$ (reverse); glyceraldehyde-3-phosphate dehydrogenase, 5'-AACTTTGGCATTGTGGAAGG-3' (forward) and 5'-GGAGACAACCAGGTCCTCAG-3' (reverse).

\section{Western Blot Analysis}

Spinal cord tissues were processed for Western blot analysis, as described previously. ${ }^{21}$ Antibodies used were polyclonal antibodies against MMP-3 (Santa Cruz Biotechnology), ZO-1 (Invitrogen), occludin (Invitrogen), claudin-5 (Invitrogen), and $\beta$-tubulin (Sigma). The primary antibodies were detected with a horseradish peroxidase-conjugated goat anti-rabbit secondary antibody (Jackson ImmunoResearch). Immunoreactive bands were visualized by chemiluminescence using Supersignal (Pierce, Rockford, IL). $\beta$-Tubulin was used as an internal control. The gels shown in figures are representative of results from three separate experiments.

\section{Gelatin Zymography}

The activities of MMP-2 and MMP-9 in the injured spinal cord were examined 1 day after injury by gelatin zymography, as described. ${ }^{20}$ For some experiments, spinal cord total lysates (50 $\mu \mathrm{g}$, at 1 day after $\mathrm{SCI}$ ) were incubated with or without recombinant active MMP-3 (final concentration, $100 \mathrm{ng} / \mathrm{mL}$; Calbiochem) and NNGH (final concentration, $60 \mu \mathrm{mol} / \mathrm{L}$; Enzo Life Sciences International) for 2 hours at $37^{\circ} \mathrm{C}$; then, gelatin zymography was performed.

\section{Evaluation of BSCB Permeability}

The permeability of BSCB was investigated with Evans Blue Dye extravasation, as described. ${ }^{20,23}$

\section{Fluorimetric Assay of MMP-3 Enzymatic Activity}

MMP-3 enzymatic activity was measured in total lysates (100 $\mu \mathrm{g})$ from spinal cord using a 5-carboxyfluorescein (5-FAM)/ QXL520 fluorescence resonance energy transfer peptide (AnaSpec Inc., San Jose, CA), as previously described. ${ }^{15}$

\section{Neutrophil Isolation}

Neutrophil isolation was performed, as previously described, with some modifications. ${ }^{24,25}$ In brief, blood was collected from mice by cardiac puncture into a $15-\mathrm{mL}$ conical tube containing acid citrate dextrose solution. Immediately after collection, whole blood was lysed in $10 \mathrm{~mL}$ of red blood cell (RBC) lysis buffer $\left(0.15 \mathrm{~mol} / \mathrm{L} \mathrm{NH}_{4} \mathrm{Cl}, 10 \mathrm{mmol} / \mathrm{L} \mathrm{KHCO}_{3}\right.$, and $0.1 \mathrm{mmol} /$ L EDTA) for 20 minutes on ice to remove red blood cells. The RBC-lysed blood solution was passed through a $100-\mu \mathrm{m}$ Nylon mesh (BD Biosciences), and then subjected to centrifugation for 5 minutes at $400 \times g$ (Hanil, Seoul, Republic of Korea). The cell pellet was lysed further in $10 \mathrm{~mL}$ of RBC lysis buffer for 10 minutes on ice and resuspended in $30 \mathrm{~mL}$ of $0.1 \mathrm{~mol} / \mathrm{L}$ PBS. The sample was centrifuged for 5 minutes at $400 \times g$ and layered onto the discontinuous Percoll gradient solution $(3 \mathrm{~mL}$ of $80 \%, 3 \mathrm{~mL}$ of $60 \%$, and $3 \mathrm{~mL}$ of $50 \%$ ). Neutrophils were recovered from $60 \% / 80 \%$ Percoll interface and after high centrifugation $\left(2500 \times g\right.$, for 30 minutes at $\left.4^{\circ} \mathrm{C}\right)$ (Sorvall RC-5 C Plus; Thermo Fisher Scientific, Lafayette, CO). Cells were washed twice with $0.1 \mathrm{~mol} / \mathrm{L}$ PBS and incubated in Dulbecco's modified Eagle's medium containing 5\% bovine serum. Isolated neutrophils were stimulated by LPS $(50 \mathrm{ng} / \mathrm{mL})$ for 3 hours. For control, $0.9 \% \mathrm{NaCl}$ solution (saline) was treated.

\section{Flow Cytometry}

Flow cytometry was performed, as previously described, with minor modifications. ${ }^{20,26}$ Spinal cords (one spinal cord per 
sample) were mechanically disrupted with a small glass Dounce homogenizer, and cell suspensions were obtained by passing the solution through a wire mesh screen (Sigma). Samples were subjected to centrifugation at $4^{\circ} \mathrm{C}$ at $1100 \mathrm{rpm}$ $(200 \times g)$ for 10 minutes (low brake). Pellets were resuspended in fetal bovine serum staining buffer (BD Biosciences) and were subjected to centrifugation at $3000 \mathrm{rpm}(1300 \times g)$ for 7 minutes, slow brake at $4^{\circ} \mathrm{C}$. Pellets were then resuspended in fetal bovine serum staining buffer. Spinal cord samples were split into several tubes, and unstained cells and isotype-matched control samples were generated from $10 \mu \mathrm{L}$ of each sample (mix of all spinal cord samples) to control for non-specific binding and autofluorescence. The following isotype control antibodies were used: phycoerythrin-labeled rat IgG2b, $\kappa$ and FITC-labeled rat IgG2b, $\kappa$ (Pharmingen, San Diego, CA). Cell counts were performed by adding $10 \mu \mathrm{L}$ of trypan blue to $10 \mu \mathrm{L}$ of each sample to optimize antibody dilutions. After blocking with Fc block (BD Biosciences) for 10 minutes at $4^{\circ} \mathrm{C}$, we stained the cells by using antibodies directly conjugated with fluorochromes. The antibodies used in the current study were anti-Gr-1 FITC, anti-CD11b FITC, and anti-CD45 phycoerythrin (BD Biosciences). All samples were then immediately analyzed with a Becton Dickinson LSR Benchtop Flow Cytometer (BD Biosciences). Forward scatter was adjusted to minimize cellular debris, and propidium iodide exclusion was used to determine cell viability. A minimum of 250,000 cells from spinal cord samples were analyzed.

\section{Spectrophotometric Assay for Intraspinal Hemorrhage}

The hemoglobin content of spinal cord tissue subjected to the experimental procedures below was quantified with a spectrophotometric assay, as described. ${ }^{27,28}$ In brief, mice were perfused with heparinized saline to remove intravascular blood, and 5-mm segments of cord, including the lesion site, were homogenized and sonicated on ice with a pulse ultrasonicator for 1 minute. After centrifugation at $13,000 \times g$ for 30 minutes, the supernatant was collected and Drabkin's reagent (Sigma Diagnostics, Charleston, WV) was added and incubated for 15 minutes. This reaction converts hemoglobin to cyanomethemoglobin, which has an absorbance at $540 \mathrm{~nm}$, and whose concentration can then be assessed by the OD of the solution at a 550-nm wavelength. To generate a standard absorbance curve, blood was obtained from control mice by cardiac puncture after anesthesia, and incremental aliquots of this blood were added to freshly homogenized spinal cord tissue obtained from WT mice; then, similar procedures were performed alongside every spinal cord tissue assay. The volume of extravascular blood was determined by comparison to the standard curve.

\section{Behavioral Tests}

Locomotor outcome after spinal cord contusion injury was assessed using the Basso Mouse Scale (BMS). ${ }^{29}$ Mice were scored in an open-field environment by randomized investigators who were blind as to the experimental conditions (H.Y.C. and T.Y.Y.). Consensus scores for each animal were averaged at each time point for a maximum of 9 points for the BMS score and 11 points for the subscore, which assess finer aspects of locomotion.

\section{Assessment of Lesion Volume and Spared White Matter}

Lesion volume was assessed by using mice used for behavioral analysis. Serial longitudinal sections ( $10 \mu \mathrm{m}$ thick) through the dorsoventral axis of the spinal cord were stained with Cresyl violet acetate, and the lesion area was determined by MetaMorph software version 7.1 (Molecular Devices, Sunnyvale, CA), as previously described. ${ }^{30}$ To assess the spared myelin, serial transverse sections ( $20 \mu \mathrm{m}$ thick) were stained with Luxol fast blue and quantitative analysis of spared WM area was performed, as previously described. ${ }^{31}$

\section{Axon Staining and Quantification}

WT and Mmp3 KO mice were anesthetized at 28 days after injury, and frozen sections were prepared as described above. For quantitative analysis of axonal densities, serial transverse sections collected every millimeter rostral and caudal $3 \mathrm{~mm}$ to the lesion site were stained with NF200 antibody. Axonal densities were determined within preselected fields $(40 \times 40$ $\mu \mathrm{m}, 1600 \mu \mathrm{m}^{2}$ ) at specific sites within the vestibulospinal tract for NF200-positive axons, as previously described. ${ }^{21}$ The location of these sites was carefully conserved from group to group using anatomical landmarks, and remaining axons were manually counted from each field. The number of axons in WT or Mmp3 $\mathrm{KO}$ mice was expressed as a percentage relative to that in sham control $(100 \%)$.

\section{Statistical Analysis}

Data represented the means \pm SEM or SD values. The normal distribution was confirmed by using the D'Agostino-Pearson test. Comparisons between WT and Mmp3 KO mice or drug-treated groups were performed by unpaired Student's $t$-test. Multiple comparisons between groups were performed using one-way analysis of variance. Behavioral scores were analyzed by repeated-measures analysis of variance (time versus treatment). Tukey's multiple comparison was used as post hoc analysis. $P<0.05$ was considered to be statistically significant. All statistical analyses were performed by using SPSS version 15.0 (SPSS Science, Chicago, IL).

\section{Results}

\section{MMP-3 Expression and Activity Increase after SCI}

Because the temporal and special profiles of MMP-3 expression after SCI are not yet known, we first determined the profile of MMP-3 expression after SCI. MMP-3 mRNA expression was not detectable in the sham control 
(Figure 1A). After SCI, MMP-3 mRNA was markedly increased at 8 hours, peaked at 1 day, and then declined (Figure 1A), as reported. ${ }^{13}$ Western blot analysis showed that the level of MMP-3 protein was also increased and peaked at 8 hours and 1 day after injury (Figure 1B). MMP-3 antibody detected two proteins (48 and $55 \mathrm{kDa}$ ), indicating that both active $(48 \mathrm{kDa})$ and pro $(55 \mathrm{kDa})$ forms of MMP-3 were induced after injury (Figure 1, B and C). By fluorescent enzymatic assay, MMP-3 activity was significantly increased from 8 hours and peaked at 1 day after injury (Figure 1D). IHC showed that MMP-3 immunoreactivity was not observed in the sham control (Figure 1E). However, strong MMP-3 immunoreactivity was detected in round cells in the lesion site (tissue loss area, within $2 \mathrm{~mm}$, including epicenter) and blood vessels in penumbra lesion at 1 day after injury (Figure 1, E and F). Double labeling revealed that MMP-3 immunoreactivity was observed in neutrophils (MPO positive) and blood vessels (CD31 positive) (Figure 1G). Although MMP-3 immunoreactivity colocalized with CD31-positive endothelial cells, mostly its immunoreactivity was observed in surrounding regions of endothelial cells, suggesting that MMP-3 may be released from endothelial cells after injury or localized to cells that comprise the neurovascular unit (Figure 1G). By contrast, MMP-3 immunoreactivity was not detected in NeuN-positive neurons, CC1-positive oligodendrocytes, GFAP-positive astrocytes, CD11b-positive microglia, and ED1-positive macrophages/ activated microglia after injury (Supplemental Figure S1). These results suggest that MMP-3 expression is up-regulated in infiltrated neutrophils and endothelial cells of blood vessels after SCI.

\section{MMP-3 Increases BSCB Permeability after SCI}

Data showing that MMP-3 expression was increased in blood vessels after injury led us to postulate that MMP-3 would induce the BSCB disruption by increasing its permeability after SCI. To investigate the BSCB permeability, we assessed Evans Blue assay after injury. The amount of Evans Blue Dye extravasation was markedly increased and peaked at 1 day, suggesting BSCB leakage (Figure 2A). Furthermore, the level of Evans Blue Dye extravasation at 8 hours and 1 day after injury was significantly lower in Mmp3 KO mice than in WT mice (Figure 2, A and B). Qualitative analysis also showed that the fluorescence intensity of Evans Blue Dye was significantly higher in WT mice than in Mmp3 $\mathrm{KO}$ mice at 1 day after injury (Figure 2, C and D). However, any signal of Evans Blue Dye was not detected in the sham or Evans Blue Dye uninjected control (Figure 2C). To further confirm the role of MMP-3 in BSCB disruption, we administrated Mmp3 siRNA at 30 minutes after SCI. When we examined the distribution of siRNAs after intraspinal injection to injured spinal cord by using the fluorescence (Cy-3)-labeled siRNAs, the injected Cy-3-labeled siRNA was observed in the spinal cord from approximately $5 \mathrm{~mm}$ caudal to $5 \mathrm{~mm}$ rostral, including lesion site at 1 day after injury (data not shown). In vivo delivery of siRNA targeting Mmp3 inhibited mRNA expression and activity of MMP-3 after SCI (Supplemental Figure S2, A and B) and significantly reduced the SCI-induced BSCB permeability (Figure 2, C-E). In addition, a general inhibitor of MMPs, NNGH treatment also significantly inhibited MMP-3 activity (Supplemental Figure S2C) and reduced the amount of Evans Blue Dye leaked into spinal cord tissues at 1 day after injury compared with vehicle-treated control mice (Supplemental Figure S2D). Furthermore, a single injection of exogenous MMP-3 (20 or 200 pmol) into normal spinal cord significantly increased Evans Blue Dye extravasation (Figure 2F), indicating that exogenous MMP-3 may be sufficient to increase BSCB permeability. These results indicate that MMP-3 up-regulation is essential for the increase of BSCB permeability after SCI.

\section{MMP-3 Contributes to Degradation of TJ Proteins of Blood Vessel after SCI}

The restrictive nature of the $\mathrm{BBB} / \mathrm{BSCB}$ that exists between adjacent endothelial cells is because of complex networks of TJ proteins, such as ZO-1, occludin, and claudin-5, that link transmembrane proteins to the actin cytoskeleton. ${ }^{32,33}$ Our previous study also showed that the degradation of TJ proteins results in BSCB disruption by increasing its permeability, and the levels of TJ proteins decrease after SCI. ${ }^{20}$ Accordingly, we examined the change of TJ protein levels after SCI and compared the difference between WT and KO mice. Western blot analyses showed that the level of ZO-1 was gradually decreased at an early time point (at 4 and 8 hours) after injury and then increased at 1 day, whereas the level of occludin $(65 \mathrm{kDa})$ was reduced at delayed time points (3 and 7 days) after injury (Figure 3, A-C). In the case of claudin-5, a lower isoform $(17 \mathrm{kDa})$ was increased at 7 days after injury (Figure 3, A and D). Similarly, fluorescence imaging of the sham spinal cord showed that ZO-1, occludin, and claudin-5 colocalized with a CD31 antibody, a marker of endothelial cells (Figure 3E). However, the immunoreactive intensity of ZO-1, occludin, and claudin-5 in blood vessels was decreased after injury, and some blood vessels were almost negative for its immunoreactivity in the lesion area (Figure 3E). These data indicate that the levels of TJ proteins in blood vessels are decreased after SCI. Furthermore, the levels of ZO-1 and occludin were significantly higher in the Mmp3 KO mice than in WT mice, and the level of degraded claudin-5 was significantly reduced in the Mmp3 KO mice (Figure 3, F-H), suggesting that MMP-3 may mediate to degrade TJ proteins after injury.

\section{MMP-3 Increases Blood Cell Infiltration and Hemorrhage after SCI}

The BSCB disruption is known to elicit blood cell infiltration, thereby inducing secondary damages, such as inflammation, which leads to neurological deficits after SCI. ${ }^{6,24,26,27}$ 


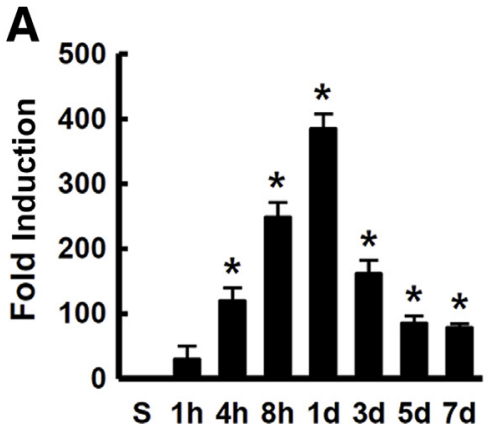

C

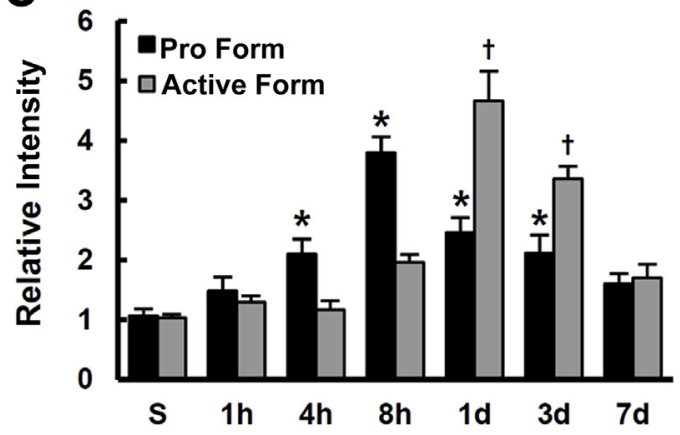

E

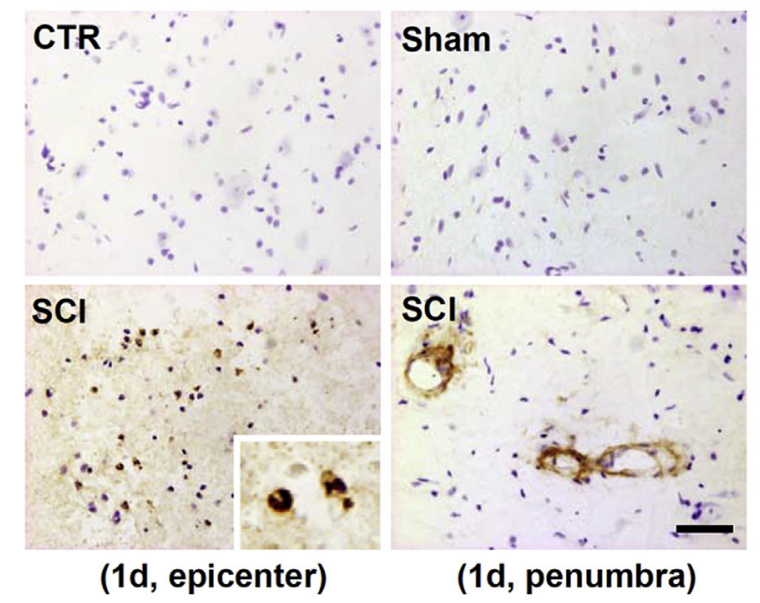

B
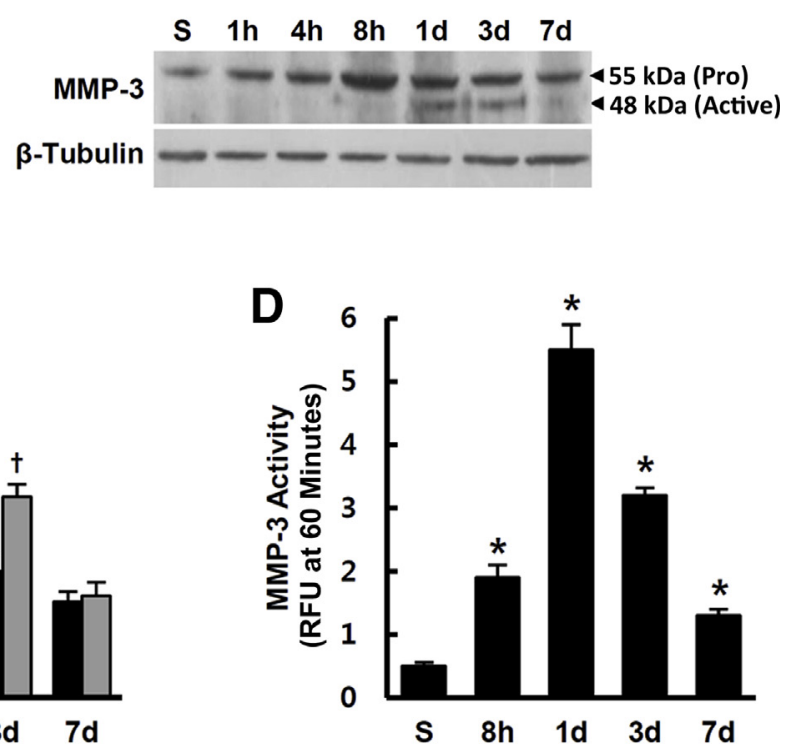

F

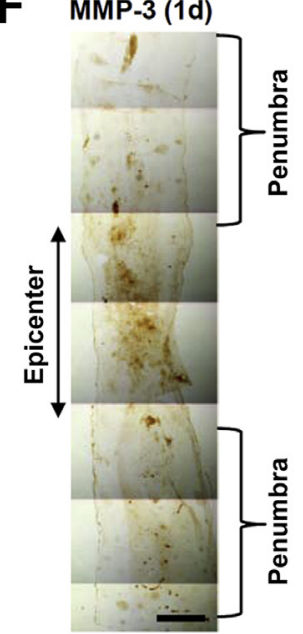

G
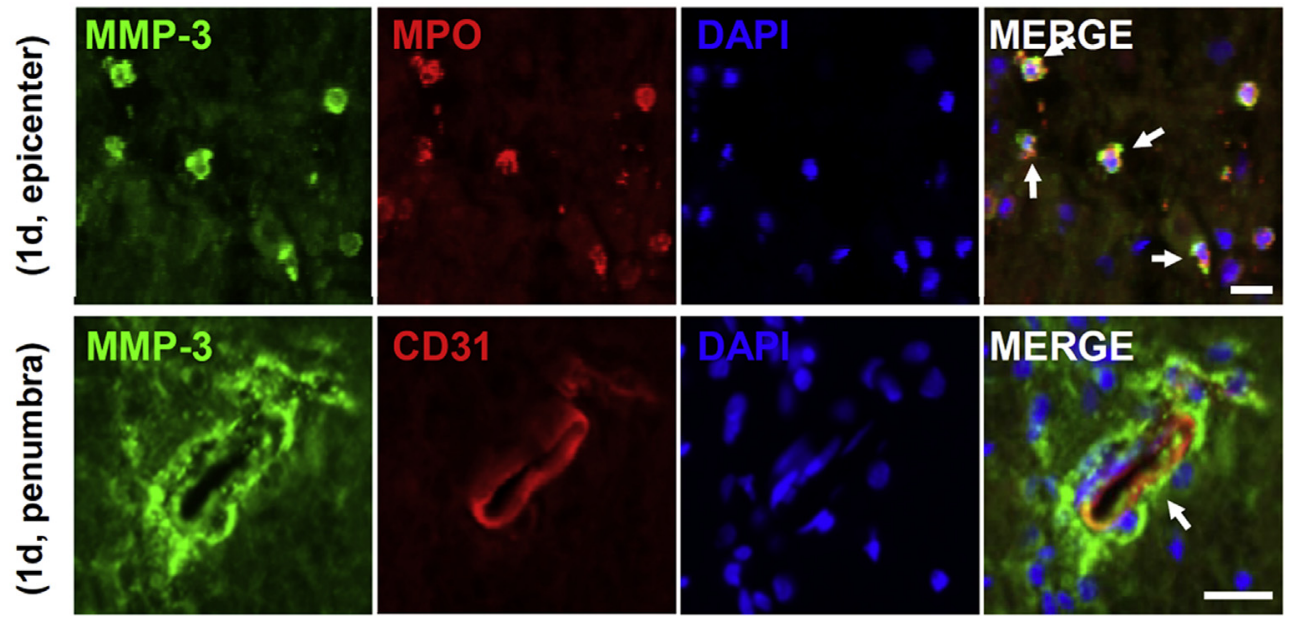

MERGE

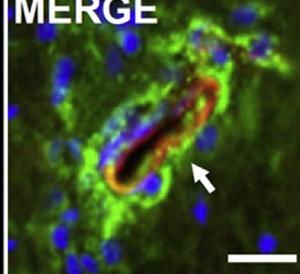


Therefore, we examined the effect of MMP-3 on blood cell infiltration after SCI by using flow cytometry. First, we determined the amount of the common leukocyte antigen, CD45-positive cells, in injured spinal cord. We found that CD45-positive cells were markedly increased compared with sham control. In addition, the percentage of CD45-positive cells was significantly decreased in $M m p 3 \mathrm{KO}$ and $M m p 3$ siRNA-injected samples (Figure 4C). Next, we determined the role of MMP-3 on infiltration of neutrophils (CD45 ${ }^{\text {high/ }}$ $\left.\mathrm{Gr}-1^{\text {high }}\right)$ and macrophages (CD $\left.45^{\text {mid }} / \mathrm{CD} 11 \mathrm{~b}^{\text {high }}\right)$ by double labeling, as previously reported. ${ }^{34}$ In uninjured spinal cords of WT mice, few neutrophils or macrophages were present in the spinal cord tissue (Figure 4, D and H). However, the proportion of neutrophils and macrophages was dramatically increased at 1 and 5 days after SCI, respectively (Figure 4, E and I). Furthermore, the number of infiltrated neutrophils and macrophages was decreased in both $M m p 3$ siRNA-injected WT mice (Figure 4, F and J) and Mmp3 KO mice (Figure 4, G and K) after injury. Quantitative analysis showed that the percentage of $\mathrm{CD} 45^{\text {high }} / \mathrm{Gr}-1^{\text {high }}$ cells (neutrophils) and CD $45^{\text {high }} / \mathrm{CD} 11 \mathrm{~b}^{\text {high }}$ cells (macrophages) among total labeled cells was significantly lower in both Mmp3 $\mathrm{KO}$ and Mmp3 siRNA-injected mice than in vehicle-treated WT mice at 1 and 5 days after injury, respectively (Figure 4, L and M). These data indicate that MMP-3 induces blood cell infiltration by increasing BSCB permeability after SCI. In addition, the volume of extravascular blood at 1 day after injury was significantly reduced in Mmp3 KO mice compared with WT mice (Figure 4, N-P), indicating that MMP-3 activation after injury results in the secondary petechial hemorrhage.

\section{NF- $\kappa B$ Mediates MMP-3 Expression after SCI}

NF- $\kappa \mathrm{B}$ has been implicated in inflammatory responses after SCI ${ }^{35,36}$ Recent evidence showed that NF- $\mathrm{KB}$ is involved in the expression and/or activation of MMPs after injury. ${ }^{24,37,38}$ To examine whether NF- $\kappa \mathrm{B}$ mediates MMP-3 expression after SCI, we used Ikk- $\beta$ conditional KO mice $\left(I k k \beta^{\Delta m y e}\right)$, in which the $I k k \beta$ gene was specifically deleted from myeloid cells, including most neutrophil and macrophage populations. ${ }^{24}$ Real-time PCR and fluorescent enzymatic assay revealed that the level of MMP-3 mRNA and activity 1 day after SCI was significantly lower in $I k k \beta^{\Delta m y e}$ mice than in WT mice (Figure 5, A and B). To further validate our results, we isolated neutrophils from WT and I $I k \beta^{\Delta m y e}$ mice, and cells were treated with LPS as a ligand to stimulate and activate
NF- $\kappa \mathrm{B}$ signaling. ${ }^{24,39}$ LPS induced a substantial increase of MMP-3 expression in neutrophils from WT mice, whereas there was no increase of MMP-3 expression in neutrophils from $I k k \beta^{\Delta m y e}$ mice by LPS (Figure 5C). This indicated that MMP-3 expression in neutrophils from Ikk $\beta^{\Delta m y e}$ mice was not induced by LPS because of lack of NF- $\kappa \mathrm{B}$ signaling. In addition, the level of Evans Blue Dye extravasation after injury was also reduced in $I k k \beta^{\Delta m y e}$ mice compared with WT mice (Figure 5, D and E). Furthermore, double labeling showed that NF- $\kappa B$ (p65) colocalized with CD31 (Figure 5F). However, NF- $\kappa \mathrm{B}$ (p65) was not expressed in the endothelial cells of uninjured spinal cord (Figure 5F). These results suggest that NF- $\kappa \mathrm{B}$ signaling mediates MMP-3 expression in neurorophils and blood vessels after SCI.

\section{MMP-3 Mediates Activation of MMP-2 and MMP-9 after SCI}

MMP-9 is up-regulated after SCI and induces BSCB disruption. ${ }^{1,6}$ However, the mechanisms underlying MMP-9 activation after SCI are largely unknown. It has been suggested that MMP-3 activates pro-MMP-9 in microglia/macrophages in cell culture. ${ }^{40}$ Therefore, we postulated that MMP-3 would mediate MMP-9 activation after SCI. Because MMP-9 activity is peaked at 1 day after SCI, ${ }^{6,20}$ we compared MMP-9 activity in WT and Mmp3 KO mice 1 day after injury by using gelatin zymography. The level of active MMP-9 was markedly increased in both WT and Mmp3 KO mice after injury. However, the MMP-9 activity was significantly lower in Mmp3 KO than in WT mice (Figure 6, A and B and Supplemental Figure S2E). Furthermore, MMP-9 activity was also inhibited by Mmp3 siRNA (Figure 6, C and D) and MMP inhibitor, NNGH (Supplemental Figure S2, F and G), treatment 1 day after SCI. To confirm these data, spinal cord lysates (from WT mice at 1 day after $\mathrm{SCI}$ ) were incubated with recombinant active MMP-3, with or without NNGH for 2 hours at $37^{\circ} \mathrm{C}$, and then MMP-9 activity was assessed by gelatin zymography. MMP-9 activity (active; 82 and $86 \mathrm{KDa}$ ) was markedly increased in the injured spinal cord lysate incubated with recombinant MMP-3 compared with lysate without MMP-3 (Figure 6E). In addition, the increase of active MMP-9 by recombinant MMP-3 was completely inhibited by NNGH treatment. Interestingly, an additional active form (82 KDa) of MMP-9 was observed when the lysate was treated with recombinant MMP-3 enzyme. Active MMP-9 appears on

Figure 1 Matrix metalloproteinase-3 (MMP-3) expression and activation increase after spinal cord injury (SCI). Total RNA and protein were prepared from the spinal cord, as described in Materials and Methods. The levels of MMP-3 mRNA (A), protein (B and C), and MMP-3 activity (D) are increased, and peak at 1 day after SCI. A: MMP-3 mRNA levels by real-time PCR. B: MMP-3 antibody detects both pro (55-kDa) and active (48-kDa) MMP-3. C: Quantitative analysis of Western blot against MMP-3. D: The activity of MMP-3 measured fluorimetrically using a 5-carboxyfluorescein (5-FAM)/QXL520 fluorescence resonance energy transfer peptide and the change in fluorescence for 60 minutes at $37^{\circ} \mathrm{C}$ measured and indicated as relative fluorescence units (RFUs). E: IHC analysis shows that MMP-3 is expressed in round cells in the epicenter (within $2 \mathrm{~mm}$, including lesion site) and blood vessels in penumbra lesion (rostral $2 \mathrm{~mm}$ to epicenter) at 1 day after SCI. Inset: Higher magnification in the epicenter. As an internal control (CTR), spinal sections were incubated with only secondary antibody without primary antibody. F: MMP-3 staining shows full spinal cord section. G: Double IHC analyses show that MMP-3 is expressed in MP0-positive neutrophils at lesion epicenter and in CD31-positive blood vessel at penumbra region (rostral $2 \mathrm{~mm}$ to epicenter, arrows) at 1 day after injury. Data represent means \pm SD $(\mathbf{A}, \mathbf{C}$, and $\mathbf{D}) .{ }^{*} P<0.05$ versus sham $(n=3 ; \mathbf{A}$ and $\mathbf{D}) ;{ }^{*} P<0.05$ versus sham for pro form, ${ }^{\dagger} P<0.05$ versus sham for active form (C). Scale bars: $50 \mu \mathrm{m}$ (E); $500 \mu \mathrm{m}(\mathbf{F}) ; 20 \mu \mathrm{m}(\mathbf{G})$. S, uninjured sham control. 

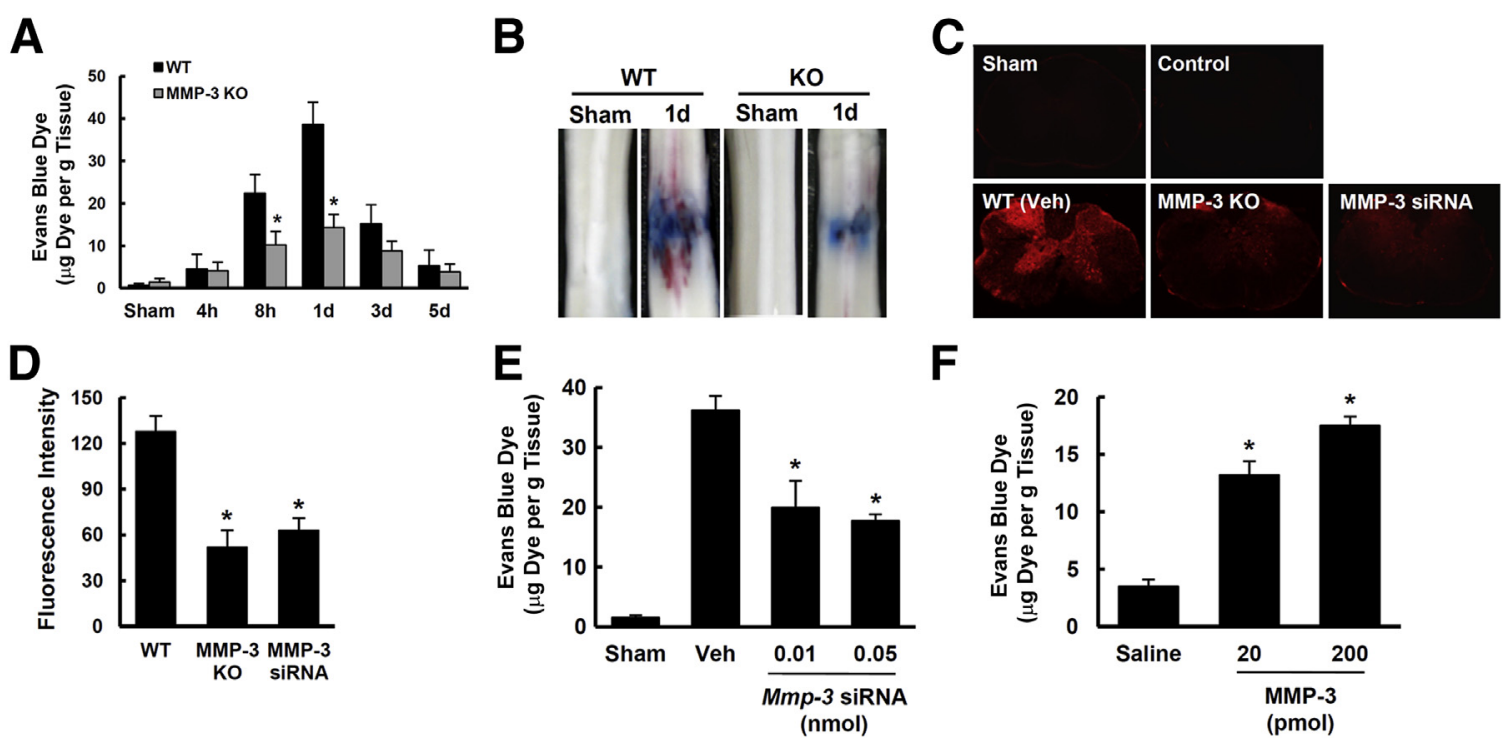

Figure 2 Matrix metalloproteinase-3 (MMP-3) increases blood-spinal cord barrier (BSCB) permeability after spinal cord injury (SCI). To measure the BSCB permeability, $0.5 \mathrm{~mL}$ of $2 \%$ Evans Blue Dye was administered i.p. at indicated time points after SCI and 3 hours later, and spinal tissues were prepared for detection and quantification of Evans Blue Dye extravasation. A: Quantification of the Evans Blue Dye extravasation by using fluorometer (excitation at $620 \mathrm{~nm}$ and emission at $680 \mathrm{~nm}$ ). Evans Blue Dye extravasation is significantly reduced in Mmp3 KO mice at 8 hours and 1 day compared with WT. The value was presented as amount of dye $(\mu \mathrm{g}) /$ tissue weight $(\mathrm{g})(n=5)$. B: Representative whole spinal cords show that Evans Blue Dye permeabilizes into spinal cord at 1 day. C: Representative confocal images of Evans Blue Dye extravasation at $1 \mathrm{~mm}$ caudal to the lesion epicenter at 1 day after SCI. Evans Blue Dye uninjected mice were used as control. D: Quantitative analysis shows that the fluorescence intensity of Evans Blue Dye is significantly reduced in Mmp3 K0 and $0.05 \mathrm{nmol}$ Mmp3 siRNA-injected mice when compared with WT. The value was presented as total fluorescence intensity obtained from rostral $2 \mathrm{~mm}$ to caudal $2 \mathrm{~mm}$ from lesion epicenter (100- $\mu \mathrm{m}$ interval; total, 40 sections) by using MetaMorph software version $7.1(n=5)$. E: Evans Blue Dye extravasation at 1 day after SCI is significantly alleviated by intraspinal injection of Mmp3 siRNA ( 0.01 or $0.05 \mathrm{nmol}$ siRNA in distilled water) at 30 minutes after injury. Data represent means \pm SEM $(n=5)$. F: Evans Blue Dye extravasation is significantly increased at 1 day after intraspinal injection of recombinant active MMP-3 (20 or 200 pmol in PBS) into normal spinal cord $(n=5)$. Data represent means \pm SEM $(\mathbf{A}, \mathbf{D}$, and $\mathbf{F}) .{ }^{*} P<0.05$ versus WT $(\mathbf{A}$ and $\mathbf{D})$; ${ }^{*} P<0.05$ versus control siRNAinjected mice $(\mathbf{E}) ;{ }^{*} P<0.05$ versus saline-injected mice $(\mathbf{F})$. Veh, vehicle.

the zymographic gel when breast cancer cells are incubated with pro-MMP-3 and plasminogen. ${ }^{41}$ Furthermore, MMP-2 appeared to be activated by MMP-3. However, when the lysate was incubated with only NNGH, both MMP-2 and MMP-9 activity was not changed by NNGH, suggesting that NNGH may not affect gelatinase activity of both MMP-2 and MMP-9 in this study. In addition, gelatinase activity did not appear when a recombinant MMP-3 alone was loaded. These results indicate that MMP- 3 mediates, in part, the activation of MMP-9 after SCI.

\section{MMP3 K0 Mice Exhibit Improved Functional Recovery and Histological Outcomes after SCI}

We finally examined whether Mmp3 deficiency influences locomotor recovery after SCI by using the 9-point BMS score and 11-point BMS subscore. ${ }^{29}$ Both scores were significantly higher in Mmp3 KO mice than WT mice at 14 to 28 days after injury (at 28 days, BMS score: WT versus Mmp3, $4.5 \pm 0.23$ versus $6.5 \pm 0.22$; BMS subscore: WT versus $M m p 3 \mathrm{KO}$, $1.2 \pm 0.21$ versus $3.7 \pm 0.3 ; n=15 ; P<0.01$ ) (Figure 7, A and $\mathrm{B}$ ). The sham group maintained the highest score (BMS score, 9; BMS subscore, 11) throughout the assessment period, which indicated no functional impairment (Figure 7, A and B). At the end of the behavioral observation period at 28 days, mice were sacrificed to determine whether MMP-3 deficiency altered the amount of spared WM and lesion volume after SCI. Luxol fast blue staining with serial sections throughout the lesion site of representative WT and Mmp3 $\mathrm{KO}$ mice at 28 days after injury are shown in Figure 7C. Quantification analysis showed that spared WM area was higher in Mmp3 KO mice than WT mice (Figure 7D). Conversely, Mmp3 KO mice had significantly less lesion volume (WT versus Mmp3 KO, $2.3 \pm 0.3 \mathrm{~mm}^{3}$ versus $1.4 \pm 0.2 \mathrm{~mm}^{3}$ ) (Figure 7E). We next addressed whether $\mathrm{Mmp} 3$ deficiency affected axonal sparing after SCI by evaluating NF200 staining. At 28 days after injury, the density of NF200-positive axons was markedly decreased and exhibited a patchy distribution. However, the number of NF200-positive axons was significantly higher in Mmp3 KO mice compared with those in WT mice (WT versus Mmp $3 \mathrm{KO}, 35 \% \pm 8 \%$ versus $66 \% \pm 7 \%$ ) (Figure $7, \mathrm{~F}$ and $\mathrm{G}$ ). These results indicated that Mmp3 deficiency results in improved locomotor function and histological outcome via inhibiting BSCB disruption after SCI.

\section{Discussion}

Our study clearly demonstrates the role of MMP-3 in BSCB disruption and blood cell infiltration, which results in functional impairment after SCI. MMP-3 expression was induced in infiltrated neutrophils and blood vessels, and increased BSCB permeability by degrading TJ proteins in endothelial cells after 
A

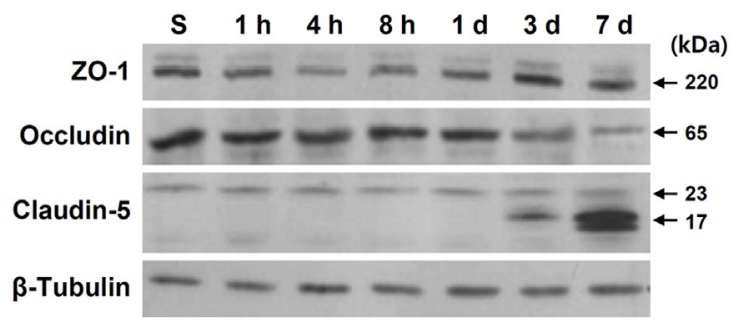

B

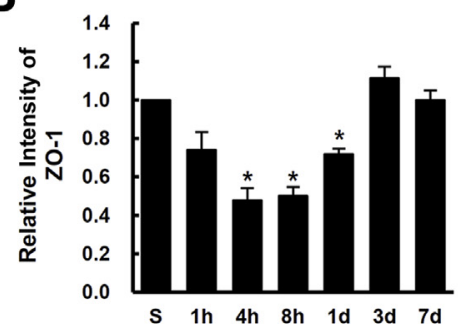

E

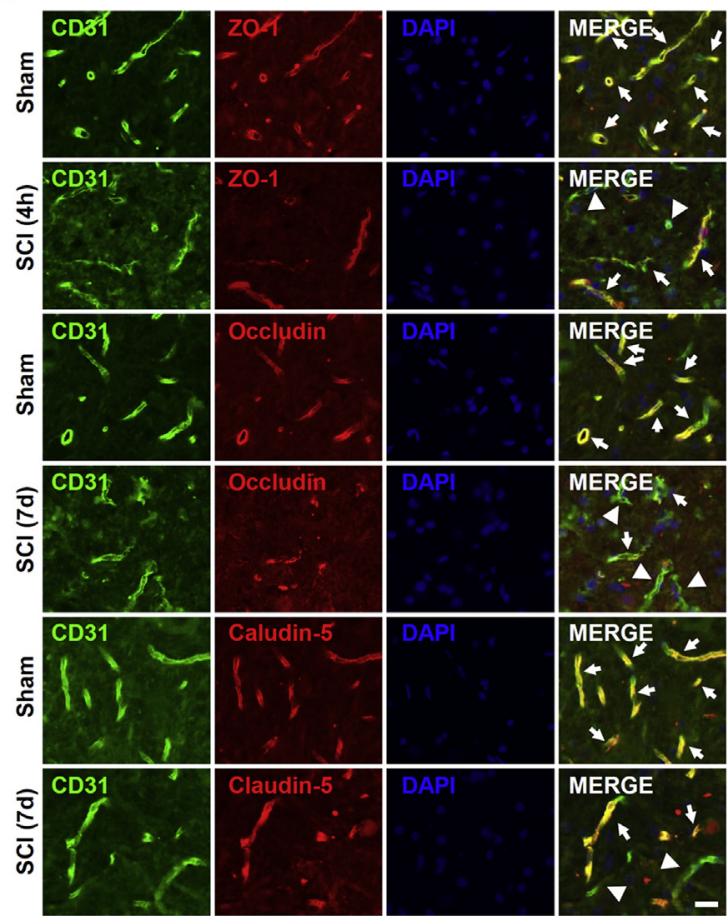

C

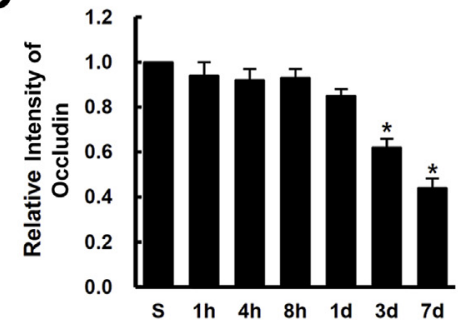

$\mathbf{F}$

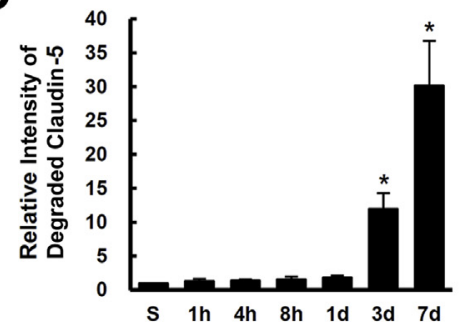

G

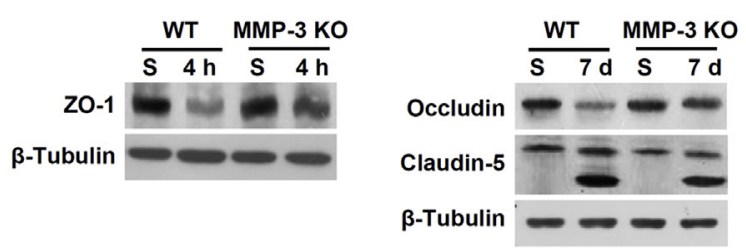

H

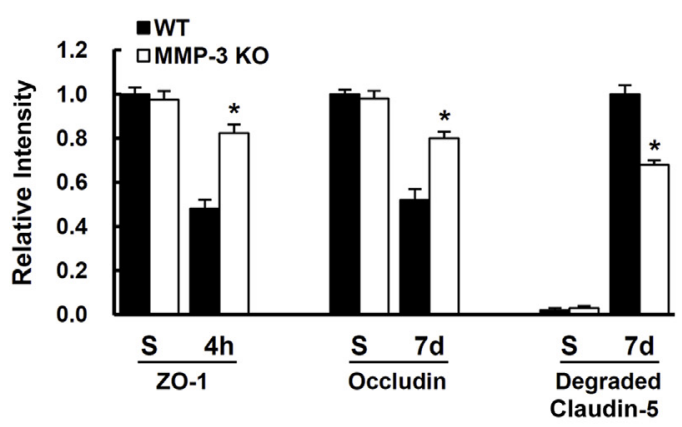

Figure 3 Matrix metalloproteinase-3 (MMP-3) contributes to tight junction (TJ) protein degradation of blood vessels after spinal cord injury (SCI). A: Western blot analyses of Z0-1, occludin, and claudin-5 at indicated time points. Quantitative analysis of Western blots against Z0-1 (B), occludin (C), and degraded caludin-5 (D) after SCI. E: Double immunofluorescence shows that TJ proteins, Z0-1, occludin, and claudin-5 colocalize in CD31 (endothelial cell marker)-positive blood vessels in sham (S) control. However, the fluorescence intensity of each TJ protein is decreased, and more fragmented blood vessels are observed in injured spinal cords of WT mice when compared with sham control. Arrows indicate each TJ protein/CD31-positive endothelial cell of blood vessels; and arrowheads, some CD31-positive endothelial cells without or with little immunoreactivity of TJ proteins in the lesion site of injured spinal cord. Tissues were selected at $500 \mu \mathrm{m}$ caudal to the lesion epicenter. Western blot analysis of Z0-1 (F) and occludin and claudin-5 (G) in WT and Mmp3 K0 mice at the indicated time point after SCI $(n=3)$. H: Quantitative analysis of Western blots shows that the level of Z0-1, occludin, and claudin-5 decreases after SCI, which is significantly inhibited in Mmp3 K0 when compared with WT mice. Data represent means \pm SD $(\mathbf{B}-\mathbf{D}$ and $\mathbf{H})$. ${ }^{*} P<0.05$ versus sham (B-D); ${ }^{*} P<0.05$ versus WT (H). Scale bar $=10 \mu \mathrm{m}(\mathbf{E})$.

injury. In addition, NF- $\kappa \mathrm{B}$ was involved in MMP-3 expression, and MMP-3 appeared to mediate MMP-9 activation after SCI. Furthermore, MMP-3 deficiency resulted in improved locomotor recovery and histological outcomes after injury compared with WT control.
Several MMPs are up-regulated after SCI, ${ }^{13}$ and MMP-9 and MMP-12 are involved in BSCB disruption after SCI. ${ }^{6,13}$ However, the role of MMP-3 on BSCB disruption after SCI has not been examined. Herein, our study elucidated the role of MMP-3 after SCI for the first time, to our knowledge. 
A

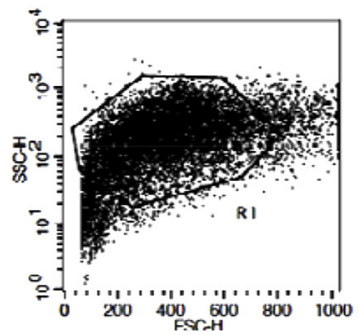

D

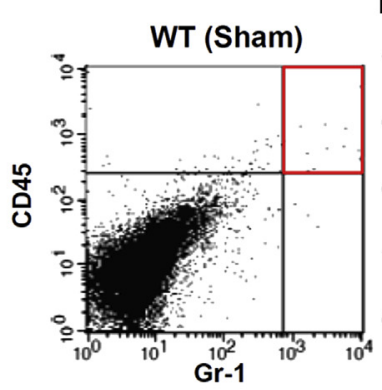

H

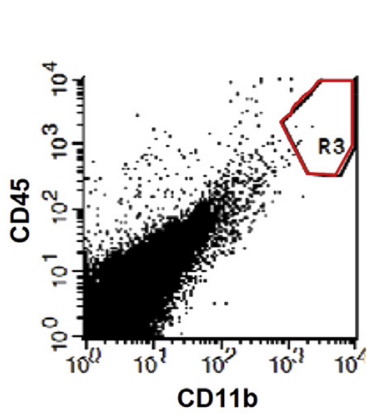

L

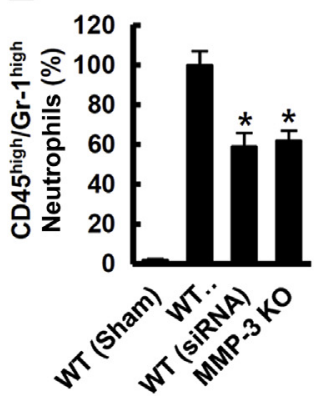

B

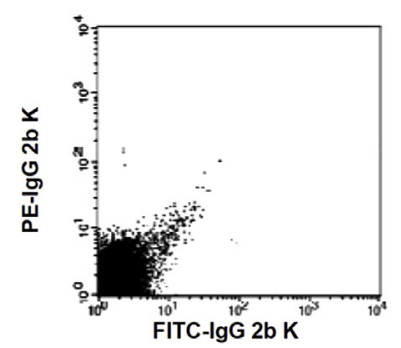

C

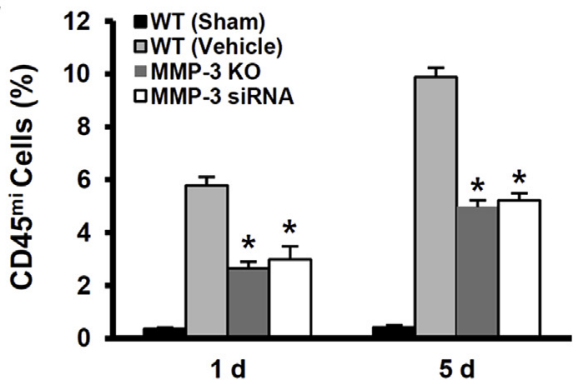

E $F$

G

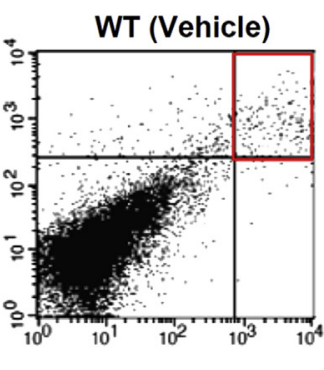

WT (siRNA)
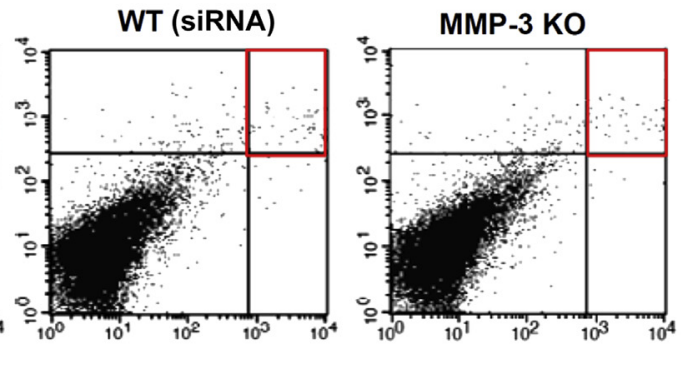

$1 \mathrm{~d}$
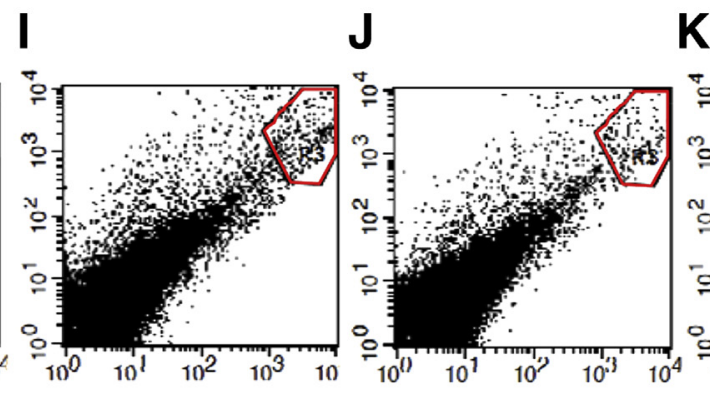

K

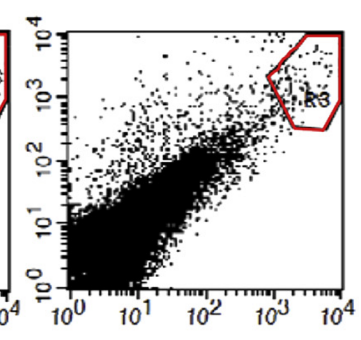

$5 d$

$\mathbf{N}$

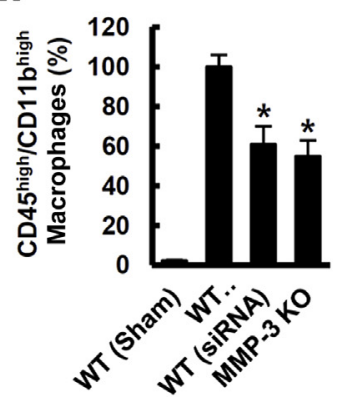

0

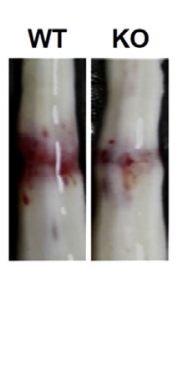

$\mathbf{P}$

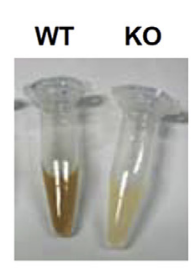

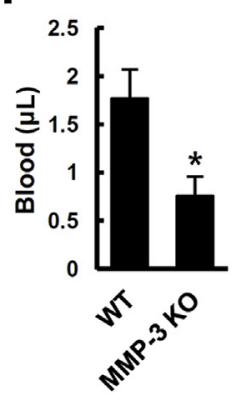

Figure 4 Matrix metalloproteinase-3 (MMP-3) increases blood cell infiltration and hemorrhage after spinal cord injury (SCI). After SCI, the numbers of neutrophils and macrophages infiltrated into spinal cord tissues at 1 and 5 days after injury were analyzed by flow cytometry after staining with CD45, Gr-1, and CD11b antibodies $(n=5)$. A: Forward scatter (FSC)-side scatter (SSC) plot. B: Isotype-only control. C: Quantification of CD45-positive cells at 1 and 5 days. Density plot of representative WT sham (D and $\mathbf{H})$, WT vehicle (E and I), WT Mmp3 siRNA (F and J), and Mmp3 K0 (G and $\mathbf{K})$-treated spinal cord samples. Quantification of CD45 high $/ G r-1^{\text {high }}$ for neutrophils (L) at 1 day and CD $45^{\text {high }} /$ CD11 $b^{\text {high }}$ for macrophages (M) at 5 days after injury as a percentage of vehicle controls. Representative whole spinal cords $(\mathbf{N})$, spinal cord homogenates in e-tube (0), and spectrophotometric quantification of blood in homogenates (P) from WT and Mmp3 KO mice show that the level of extravascular blood at 1 day after injury is significantly reduced in Mmp3 KO mice compared with WT mice $(n=5)$. Data represent means \pm SEM $(\mathbf{C}, \mathbf{L}, \mathbf{M}$, and $\mathbf{P})$. ${ }^{*} P<0.05$ versus vehicle-treated WT $(\mathbf{C}, \mathbf{L}$, and $\mathbf{M}) ;{ }^{*} P<0.05$ versus WT $(\mathbf{P})$.

Disruption of BBB, including BSCB after SCI due to the loss or degradation of TJ proteins, results in blood cell infiltration, which initiates inflammatory responses and contributes to progressive neuronal dysfunction in central nervous system (CNS) diseases, such as amyotrophic lateral sclerosis (ALS), ischemia, and traumatic SCI. ${ }^{3,5,20,42}$ The TJs are important structural components of the BBB, which span the apical region of the interendothelial clefts and restrict paracellular permeability. ${ }^{43}$ The transmembrane proteins, occludin and claudin-5, form the primary seal of the TJ. They bind to the ZO-1 and other proteins that couple TJ to the actin cytoskeleton of endothelial cells. ${ }^{44}$ Evidence indicates that 

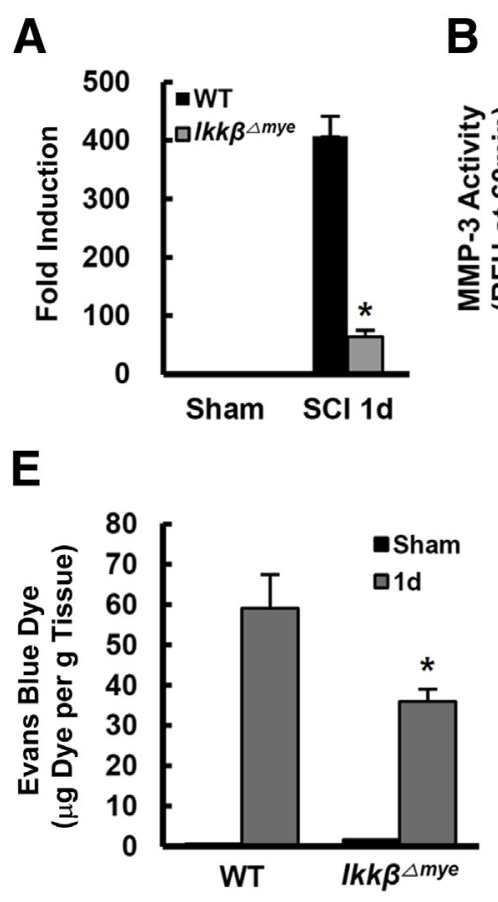
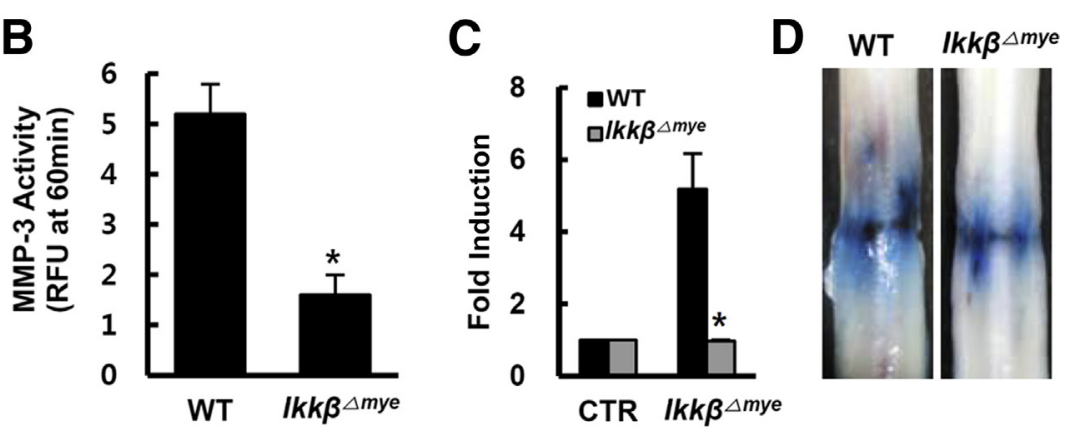

$\mathbf{F}$
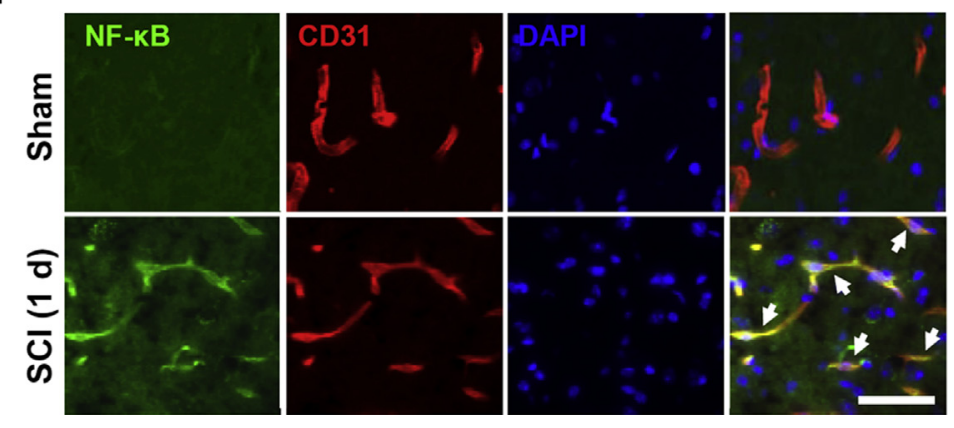

Figure 5 NF- $\kappa$ B mediates matrix metalloproteinase-3 (MMP-3) expression after spinal cord injury (SCI). Total RNA was prepared from the spinal cord of WT and $I k k \beta^{\Delta m y e}$ at 1 day after SCI and from the LPS-treated neutrophil isolated from WT and Ikk $\beta^{\Delta m y e}$. A: Real-time PCR shows that MMP-3 mRNA level is significantly reduced in injured spinal cord from $\mathrm{Ikk}^{-1-}$ mice when compared with WT $(n=3)$. B: The fluorimetric MMP-3 activity is significantly inhibited in $I k k^{-1-}$ mice when compared with WT $(n=3)$. C: Real-time PCR of MMP-3 in LPS-treated neutrophils $(n=3)$. Representative images (D) and quantitative analysis (E) show that the Evans Blue Dye extravasation was significantly reduced in Ikk $\beta^{\Delta m y e}$ when compared with WT 1 day after injury $(n=3)$. F: IHC analysis shows that NF-KB (p65) is not observed in CD31-positive blood vessels in sham control. However, NF- $\mathrm{BB}$ (p65) colocalizes with CD31-positive blood vessels at 1 day after injury (arrows). Tissues were selected at $1000 \mu \mathrm{m}$ caudal to the lesion epicenter. Images were obtained using an 0lympus BX-51 microscope connected via CoolSNAP (Tokyo, Japan). Data represent means \pm SEM (A-C and E). ${ }^{\star} P<0.05$ versus WT. Scale bar $=50 \mu \mathrm{m}(\mathbf{F})$. Original magnification, $\times 20($ D) $; \times 200($ F). RFU, relative fluorescence unit.

MMP-mediated TJ disruption is an important mechanism leading to an increase in BBB permeability after CNS injuries, such as ischemia. ${ }^{45-47}$ Our data showed that MMP-3 is upregulated after SCI and mainly observed in neutrophils and blood vessels. In addition, MMP-3 mediates BSCB disruption by degradation of TJ proteins, such as ZO-1, occludin, and claudin-5. Mmp3 KO mice exhibited significantly less disruption of the BSCB, inhibition of TJ protein degradation, attenuation of the infiltration of neutrophils and macrophages, and significant locomotor recovery compared with WT mice (Figures 2, 3, 4, and 7). Thus, our data imply that MMP-3 induces BSCB disruption, in part, by contributing to degradation of TJ proteins and can be a therapeutic target for blocking BSCB breakdown. However, we cannot exclude the possibility that other MMPs, such as MMP-2 and MMP-9, may also contribute to degradation of TJ proteins after SCI. In addition, we found a significant increase of the $17-\mathrm{kDa}$ claudin-5 band at 3 and 7 days after injury (Figure 3A), although claudin- 5 has a molecular weight normally of $23 \mathrm{kDa}$. On the basis of the recent reports, the lower molecular weight claudin- 5 may be a degraded form ${ }^{47}$ or perhaps the claudin- 5 in the new vessels is being incorporated. ${ }^{48}$ In our data, BSCB permeability after injury was more reduced in $\mathrm{Mmp} 3 \mathrm{KO}$ mice than in WT mice, and the 17-kDa claudin-5 level was significantly reduced in the $M m p 3 \mathrm{KO}$ mice (Figure 3G). Therefore, we think that the 17-kDa claudin-5 might be a degraded form. Further studies are needed to elucidate the potential role of MMP-3 in angiogenesis with time.

NF- $\kappa \mathrm{B}$ is involved in the expression and/or activation of MMPs after injury. For example, the inhibition of NF- $\kappa \mathrm{B}$ reduces the levels of activated MMP-2 and MMP-9 after cardiac global ischemia/reperfusion. ${ }^{49} \mathrm{NF}-\kappa \mathrm{B}$ is also involved in tumor necrosis factor- $\alpha$-induced up-regulation of MMP-12 in the human alveolar epithelial A549 cell line ${ }^{37}$ and is known to mediate MMP-9 expression after SCI in $I k k-\beta$ conditional KO mice. ${ }^{24}$ Furthermore, tissue plasminogen activator treatment deteriorates intracranial bleeding via low-density lipoprotein receptor-related protein/NF- $\mathrm{KB}-$ dependent MMP-3 induction in the ischemic model. ${ }^{38}$ Our data also showed that MMP-3 expression and activity was inhibited in $I k k-\beta$ conditional KO mice compared with WT mice, which resulted in reduction of BSCB disruption after SCI (Figure 5). In addition, double staining with CD31 antibody showed that MMP-3 colocalized in blood vessels after injury (Figures $1 \mathrm{~F}$ and $5 \mathrm{~F}$ ). These data demonstrated that MMP-3 expression in blood vessels after $\mathrm{SCI}$ is also dependent on NF- $\mathrm{KB}$.

Extensive evidence showed that inflammatory cells, such as neutrophils and macrophages, are infiltrated after BSCB disruption, produce inflammatory mediators (eg, tumor necrosis factor- $\alpha$, IL-1 $\beta$, IL-6, inducible nitric oxide 


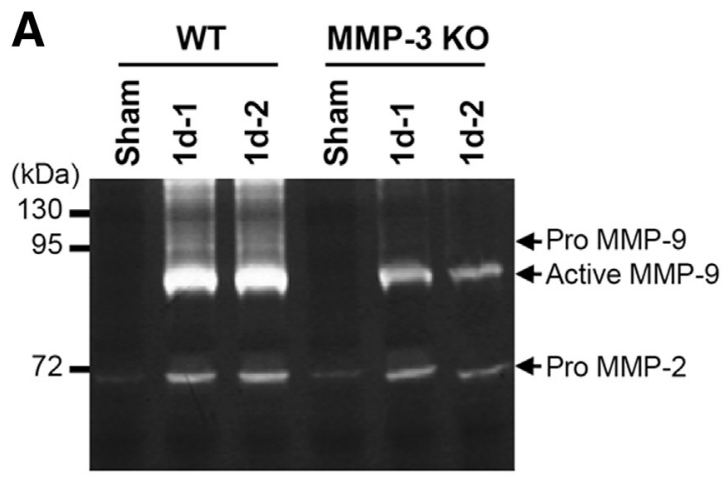

C

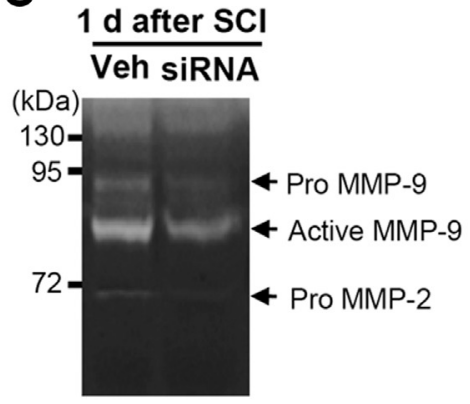

D

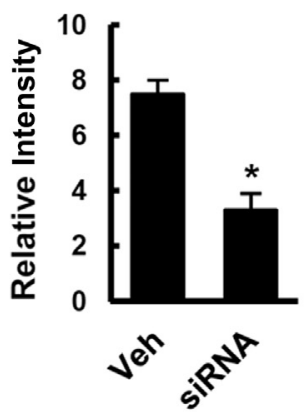

B
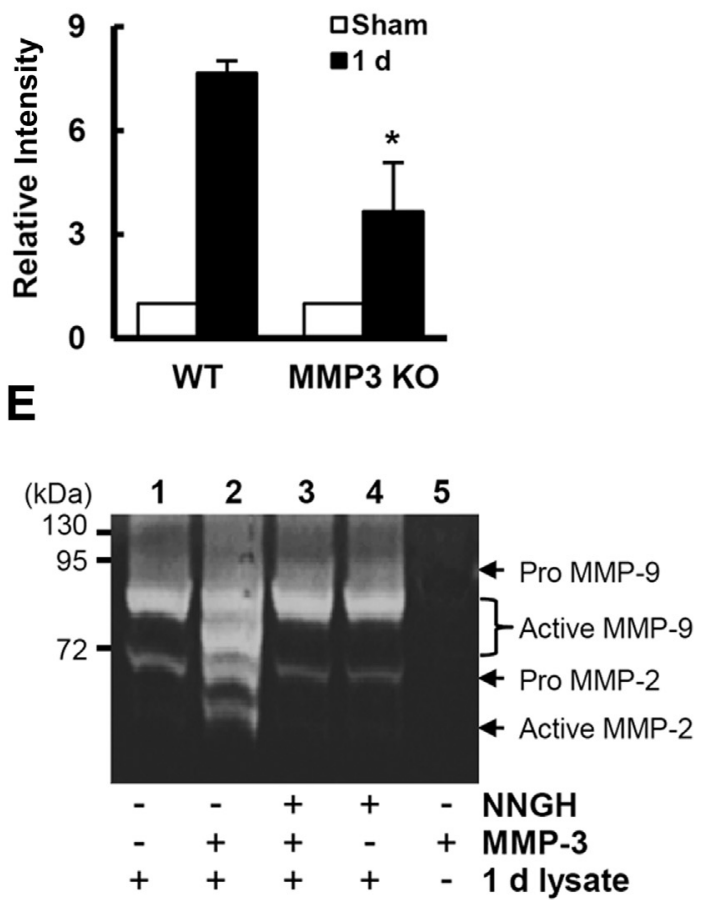

Figure 6 Matrix metalloproteinase-3 (MMP-3) mediates MMP-9 activation after spinal cord injury (SCI). Total extracts were prepared from spinal cord at 1 day after SCI, and gelatin zymography was performed. A: Gelatin zymography in WT or Mmp3 KO mice. Representative gel shows the individual MMP-9 activity of injured two animals ( $1 \mathrm{~d}-1$ and $1 \mathrm{~d}-2$ ) of WT or Mmp3 K0 group. The gelatinase activity in Mmp3 KO mice is much lower than in WT mice, although there is a little individual difference. B: Densitometric analysis of zymography $(n=3)$. The level of active MMP-9 is significantly decreased in Mmp3 mice when compared with WT. Gelatin zymography (C) and quantification analysis (D) show that intraspinal administration of Mmp3 siRNA (0.05 nmol) significantly decreases the gelatinase activity of MMP-9 at 1 day after injury compared with vehicle control $(n=5)$. E: Gelatin zymography also shows that when spinal cord lysates $(50 \mu \mathrm{g})$ prepared 1 day after injury are incubated with or without recombinant MMP-3 $(100 \mathrm{ng} / \mathrm{mL})$ and N-isobutyl-N-(4-methoxyphenylsulfonyl) glycyl hydroxamic acid (NNGH, final concentration, $60 \mu \mathrm{mol} / \mathrm{L}$ ) for 2 hours at $37^{\circ} \mathrm{C}$, pro-MMP-9 is further cleaved by MMP-3, which is attenuated by NNGH. Data represent means \pm SEM (B and $\mathbf{D}) .{ }^{*} P<0.05$ versus WT $(\mathbf{B}) ; P<0.05$ versus vehicle (control siRNA)-treated mice (D).

synthase, and cyclooxygenase-2), and induce cell death, ultimately impairing motor function after injury. ${ }^{50-53}$ In addition, the number of infiltrating neutrophils significantly correlates with the amount of tissue damage after SCI. ${ }^{53}$ Several studies demonstrate that suppression of neutrophil and macrophage infiltration after injury attenuates apoptotic cell death and improves functional recovery. ${ }^{54-56}$ Our data show that the numbers of infiltrated neutrophils and macrophages were significantly lower in Mmp3 KO mice than WT mice after injury. In addition, Mmp3 KO mice showed significantly improved locomotion recovery and histological outcomes after injury when compared with WT control (Figure 7). Furthermore, we observed that the apoptotic cell death after SCI was reduced in Mmp3-deficient mice (unpublished data, T.Y.Y.). Thus, the improved functional recovery in Mmp3 KO mice after injury appears to be attributed to decreased blood cell infiltration and subsequent inflammatory responses in Mmp3 $\mathrm{KO}$ compared with WT mice. Although we did not determine the effect of Mmp3 $\mathrm{KO}$ on the expression of inflammatory cytokines, we anticipate that the levels of cytokines are likely lower in Mmp3 $\mathrm{KO}$ mice after injury compared with WT mice. Furthermore, our preliminary study showed that microglial activation at 5 days after injury was significantly reduced in Mmp3 KO mice when compared with WT control. Thus, there is also a possibility that MMP-3 may induce apoptotic cell death by activating microglia and thereby producing inflammatory cytokines after SCI. MMP-3 released from damaged neurons activates microglia and subsequently exacerbates neuronal degeneration in the N-methyl4-phenyl-1,2,3,4-tetrahydropyridine-injected animal model of Parkinson's disease. ${ }^{57,58}$ Recently, the causality for BSCB breakdown and motor neuron degeneration was also suggested in chronic neurological disorders, such as ALS. Zhong et $\mathrm{al}^{59}$ showed that BSCB breakdown precedes spinal motor neuron injury in ALS-linked superoxide dismutase 1 mutants. In addition, treatment with an activated protein $\mathrm{C}$ analogue restored BSCB integrity and delayed onset of motor-neuron impairment and degeneration in mice with ALS. ${ }^{60,61}$ The evidence suggests that $\mathrm{BBB} / \mathrm{BSCB}$ disruption plays a pivotal role in acute and chronic neurological disorders. The inhibition of MMP-3 may be a promising therapeutic target for human CNS disease, including SCI.

Another important finding is the identification of MMP-3 as a regulator underlying the activation of MMP-9 after SCI. 


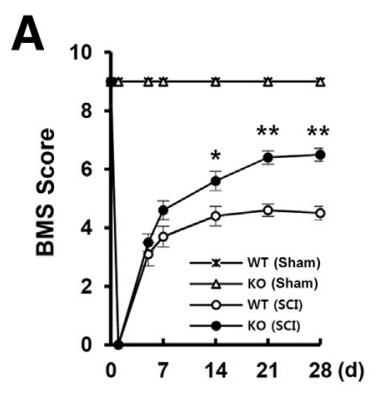

D

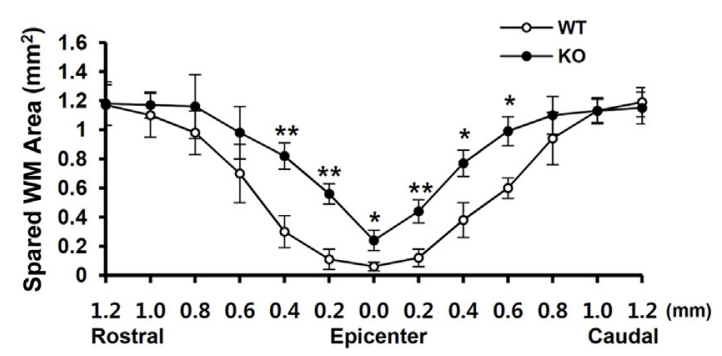

B

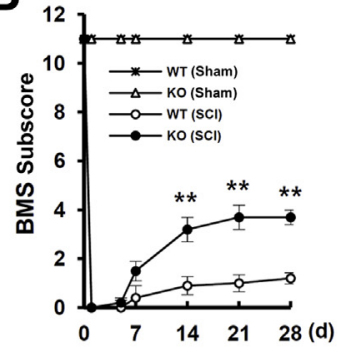

E

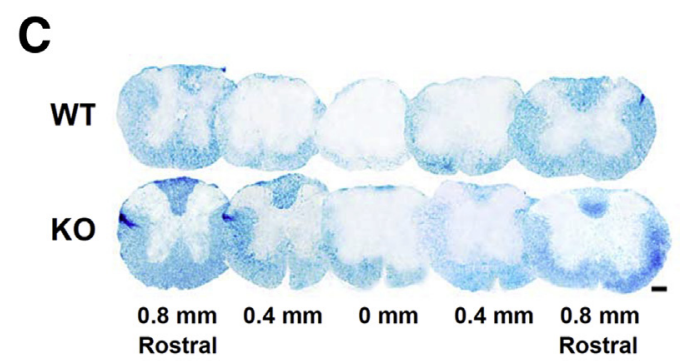

G
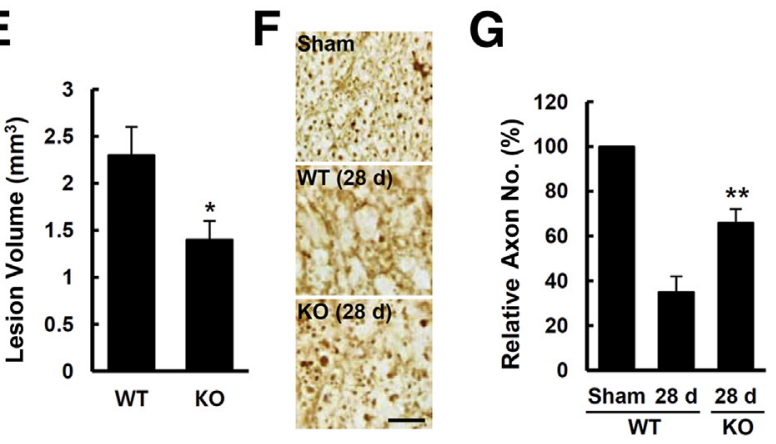

Figure 7 Functional recovery is more improved in Mmp3 K0 mice than in WT mice. After spinal cord injury (SCI), functional recovery was assessed with the BMS score (A) and BMS subscore (B) for 28 days after SCI $(n=15)$. Mmp3 K0 mice exhibit greater locomotor recovery when compared with WT. Repeatedmeasures analysis of variance: time, $P<0.01$ versus 0 days; treatment effect, ${ }^{*} P<0.05$, ${ }^{*} P<0.01$ versus WT. C: Representative Luxol fast blue-stained serial sections throughout the lesion site from WT and Mmp3 mice at 28 days after injury. At the lesion epicenter, more spared WM and smaller lesions are evident in the Mmp3 KO mice. Quantification of spared WM (D) and lesion volume (E) reveals significantly increased spared WM and reduced lesion volume in Mmp3 KO mice when compared with WT. F: Neurofilament 200 staining shows that more axons are observed in the Mmp3 K0 compared with the WT. Representative images were selected $1 \mathrm{~mm}$ rostral to the lesion site. G: Quantitative analysis of NF200-stained axons within the vestibulospinal tract shows that the number of axons in Mmp3 K0 is significantly higher than that in WT. Data represent means $\pm \mathrm{SEM}(\mathbf{A}, \mathbf{B}, \mathbf{D}, \mathbf{E}$, and $\mathbf{G})$. ${ }^{*} P<0.05,{ }^{* *} P<0.01$ versus WT. Scale bars: $100 \mu \mathrm{m}$ (C); $20 \mu \mathrm{m}$ (F).

MMP-9 is known to contribute to early secondary pathogenesis by disrupting the $\mathrm{BBB} / \mathrm{BSCB}$ in $\mathrm{CNS}$ injuries, including SCI. ${ }^{6,9}$ However, which molecule is involved in the activation of MMP-9 after SCI has not been demonstrated. Our study showed that MMP-9 activity was reduced in Mmp3 KO mice when compared with WT mice and also inhibited by Mmp3 siRNA (Figure 6, A-D). Furthermore, when a recombinant active MMP-3 was incubated with spinal cord lysates, the gelatinase activity of MMP-9 was markedly increased (Figure 6E). These results suggest that MMP-3 contributes, in part, to the activation of MMP-9 after SCI. Although MMP-3 has been suggested as one of the pro-MMP-9 activators on the basis of in vitro kinetic and catalytic parameters, ${ }^{62}$ and the report by Ramos-DeSimone et $\mathrm{al}^{41}$ showed that plamsin/ MMP-3 can activate MMP-9 and enhances tumor cell invasion, this is the first study to demonstrate that MMP-3 is involved in MMP-9 activation in CNS injury. However, the mechanism of how MMP-3 activates MMP-9 after SCI remains to be determined. Furthermore, we need to further study whether MMP-3 is also involved in MMP-2 activation after SCI.

It has been known that NNGH inhibits the activity of MMPs $1,2,3,9,10,12$, or $20 .{ }^{63-66}$ In this study, NNGH significantly inhibited MMP-3 activity after SCI (Supplemental Figure S1C). In addition, NNGH did not influence to the gelatinase activity when spinal cord lysates were incubated with NNGH in vitro (Figure 6E), and the inhibitory effect of NNGH was shown only when recombinant MMP-3 enzyme was added to the lysate (Figure 7E). Although more careful studies are necessary to reach to solid conclusions, these results suggest that the decrease of MMP-2 and MMP-9 activities in the NNGH-treated spinal cord likely occurred, at least in part, by inhibiting MMP-3. However, we cannot exclude the direct inhibitory effect of NNGH on other MMPs. We also detected MMP-3 activity by using 55-FAM/QXL520 fluorescence resonance energy transfer peptide (AnaSpec Inc.), although MMP-3 activity by using casein zymography was not detected after SCI. ${ }^{67}$ The discrepancy in detection of MMP-3 activity after SCI may be attributable to the amount of protein ( 5 versus $100 \mu \mathrm{g})$ and the detection sensitivity by analysis tool (zymography versus fluorimetric assay kit). In addition, 5-FAM/QXLTM520 fluorescence resonance energy transfer peptide can also be cleaved by MMP-12, according to data sheet. However, MMP-12 expression was low at 1 day and increased from 5 days after injury (Supplemental Figure S3). Therefore, we think that at least the fluorimetric activity detected until 3 days after injury is MMP-3 activity, although the activity of MMP-12 can be detected by the MMP3 activity kit.

Recent evidence suggests that pericytes and astrocytes may play important roles in BBB integrity. The products from pericytes may be involved in initiating $\mathrm{TJ}$ formation, and astrocytes may participate in TJ formation by stabilizing the endothelial cells and inducing protein expression changes in the endothelial cells. ${ }^{68}$ Pericytes also regulate BBB 
permeability by regulating BBB-specific gene expression patterns in endothelial cells and/or by inducing polarization of astrocyte end feet surrounding CNS blood vessels. ${ }^{69}$ Furthermore, the pericyte-endothelial cell interaction also is involved in endothelial MMP-9 production in brain capillary endothelial cell cultures, ${ }^{70}$ and a recent report shows that pericytes can also disrupt the endothelial CNS barrier by activating cyclophilin A/NF-кB/MMP-9 pathway through a lipoprotein receptor. ${ }^{71}$ However, the precise roles of pericytes and astrocytes in MMP expression in the normal and pathological BBB/ BSCB have not been determined yet. Further study is required to elucidate the relationship between these cells and MMP expression in BSCB after SCI.

Overall, our results provide that SCI-induced MMP-3, produced in neutrophils and endothelial cells, may play a pivotal role in BSCB disruption, cell death, and functional deficit after SCI and suggest that the inhibition of MMP-3 may be considered as an important therapeutic strategy to attenuate cell deaths by blocking the BBB/BSCB disruption after brain ischemia and SCI in humans.

\section{Acknowledgments}

We thank Drs. Tong Hyup Cho (Cornell University, Ithaca, NY) and Sung Joong Lee (Seoul National University, Seoul, Republic of Korea) for Mmp3 KO and Ikk KO mice, respectively.

\section{Supplemental Data}

Supplemental material for this article can be found at http://dx.doi.org/10.1016/j.ajpath.2014.07.016.

\section{References}

1. Yu F, Kamada H, Niizuma K, Endo H, Chan PH: Induction of mmp-9 expression and endothelial injury by oxidative stress after spinal cord injury. J Neurotrauma 2008, 25:184-195

2. Bartanusz V, Jezova D, Alajajian B, Digicaylioglu M: The bloodspinal cord barrier: morphology and clinical implications. Ann Neurol 2011, 70:194-206

3. Hawkins BT, Davis TP: The blood-brain barrier/neurovascular unit in health and disease. Pharmacol Rev 2005, 57:173-185

4. Zlokovic BV: The blood-brain barrier in health and chronic neurodegenerative disorders. Neuron 2008, 57:178-201

5. Abbott NJ, Ronnback L, Hansson E: Astrocyte-endothelial interactions at the blood-brain barrier. Nat Rev Neurosci 2006, 7:41-53

6. Noble LJ, Donovan F, Igarashi T, Goussev S, Werb Z: Matrix metalloproteinases limit functional recovery after spinal cord injury by modulation of early vascular events. J Neurosci 2002, 22:7526-7535

7. Sternlicht MD, Lochter A, Sympson CJ, Huey B, Rougier JP, Gray JW, Pinkel D, Bissell MJ, Werb Z: The stromal proteinase MMP3/stromelysin1 promotes mammary carcinogenesis. Cell 1999, 98:137-146

8. Werb Z: ECM and cell surface proteolysis: regulating cellular ecology. Cell 1997, 91:439-442

9. Rosenberg GA, Estrada EY, Dencoff JE: Matrix metalloproteinases and TIMPs are associated with blood-brain barrier opening after reperfusion in rat brain. Stroke 1998, 29:2189-2195
10. Liu W, Hendren J, Qin XJ, Shen J, Liu KJ: Normobaric hyperoxia attenuates early blood-brain barrier disruption by inhibiting MMP-9mediated occludin degradation in focal cerebral ischemia. J Neurochem 2009, 108:811-820

11. Gurney KJ, Estrada EY, Rosenberg GA: Blood-brain barrier disruption by stromelysin-1 facilitates neutrophil infiltration in neuroinflammation. Neurobiol Dis 2006, 23:87-96

12. Mun-Bryce S, Rosenberg GA: Gelatinase B modulates selective opening of the blood-brain barrier during inflammation. Am J Physiol 1998, 274:R1203-R1211

13. Wells JE, Rice TK, Nuttall RK, Edwards DR, Zekki H, Rivest S, Yong VW: An adverse role for matrix metalloproteinase 12 after spinal cord injury in mice. J Neurosci 2003, 23:10107-10115

14. Ishrat T, Sayeed I, Atif F, Hua F, Stein DG: Progesterone and allopregnanolone attenuate blood-brain barrier dysfunction following permanent focal ischemia by regulating the expression of matrix metalloproteinases. Exp Neurol 2010, 226:183-190

15. Aid S, Silva AC, Candelario-Jalil E, Choi SH, Rosenberg GA, Bosetti F: Cyclooxygenase-1 and -2 differentially modulate lipopolysaccharideinduced blood-brain barrier disruption through matrix metalloproteinase activity. J Cereb Blood Flow Metab 2010, 30:370-380

16. Chung YC, Kim YS, Bok E, Yune TY, Maeng S, Jin BK: MMP-3 contributes to nigrostriatal dopaminergic neuronal loss, $\mathrm{BBB}$ damage, and neuroinflammation in an MPTP mouse model of Parkinson's disease. Mediators Inflamm 2013, 2013:370526

17. Li AJ, Wang Q, Dinh TT, Ritter S: Simultaneous silencing of Npy and Dbh expression in hindbrain $\mathrm{A} 1 / \mathrm{C} 1$ catecholamine cells suppresses glucoprivic feeding. J Neurosci 2009, 29:280-287

18. Leong DJ, Gu XI, Li Y, Lee JY, Laudier DM, Majeska RJ, Schaffler MB, Cardoso L, Sun HB: Matrix metalloproteinase-3 in articular cartilage is upregulated by joint immobilization and suppressed by passive joint motion. Matrix Biol 2010, 29:420-426

19. Yune TY, Park HG, Lee JY, Oh TH: Estrogen-induced Bcl-2 expression after spinal cord injury is mediated through phosphoinositide-3-kinase/Akt-dependent CREB activation. J Neurotrauma 2008, 25:1121-1131

20. Lee JY, Kim HS, Choi HY, Oh TH, Yune TY: Fluoxetine inhibits matrix metalloprotease activation and prevents disruption of bloodspinal cord barrier after spinal cord injury. Brain 2012, 135: $2375-2389$

21. Yune TY, Lee JY, Jung GY, Kim SJ, Jiang MH, Kim YC, Oh YJ, Markelonis GJ, Oh TH: Minocycline alleviates death of oligodendrocytes by inhibiting pro-nerve growth factor production in microglia after spinal cord injury. J Neurosci 2007, 27: $7751-7761$

22. Hong J, Cho IH, Kwak KI, Suh EC, Seo J, Min HJ, Choi SY, Kim CH, Park SH, Jo EK, Lee S, Lee KE, Lee SJ: Microglial Tolllike receptor 2 contributes to kainic acid-induced glial activation and hippocampal neuronal cell death. J Biol Chem 2010, 285: 39447-39457

23. Gibson JG, Evans WA: Clinical studies of the blood volume, I: clinical application of a method employing the azo dye "Evans blue" and the spectrophotometer. J Clin Invest 1937, 16:301-316

24. Kang J, Jiang MH, Min HJ, Jo EK, Lee S, Karin M, Yune TY, Lee SJ: IKK-beta-mediated myeloid cell activation exacerbates inflammation and inhibits recovery after spinal cord injury. Eur J Immunol 2011, 41:1266-1277

25. Yuan Y, Fleming BP: A method for isolation and fluorescent labeling of rat neutrophils for intravital microvascular studies. Microvasc Res 1990, 40:218-229

26. Stirling DP, Yong VW: Dynamics of the inflammatory response after murine spinal cord injury revealed by flow cytometry. J Neurosci Res 2008, 86:1944-1958

27. Simard JM, Woo SK, Norenberg MD, Tosun C, Chen Z, Ivanova S, Tsymbalyuk O, Bryan J, Landsman D, Gerzanich V: Brief suppression of Abcc8 prevents autodestruction of spinal cord after trauma. Sci Transl Med 2010, 2:28ra29 
28. van Kampen E, Zijlstra WG: Standardization of hemoglobinometry, II: the hemiglobincyanide method. Clin Chim Acta 1961, 6: $538-544$

29. Basso DM, Fisher LC, Anderson AJ, Jakeman LB, McTigue DM, Popovich PG: Basso Mouse Scale for locomotion detects differences in recovery after spinal cord injury in five common mouse strains. J Neurotrauma 2006, 23:635-659

30. Lee JY, Chung H, Yoo YS, Oh YJ, Oh TH, Park S, Yune TY: Inhibition of apoptotic cell death by ghrelin improves functional recovery after spinal cord injury. Endocrinology 2010, 151: 3815-3826

31. Donnelly DJ, Longbrake EE, Shawler TM, Kigerl KA, Lai W, Tovar CA, Ransohoff RM, Popovich PG: Deficient CX3CR1 signaling promotes recovery after mouse spinal cord injury by limiting the recruitment and activation of Ly6Clo/iNOS+ macrophages. J Neurosci 2011, 31:9910-9922

32. Bazzoni G, Dejana E: Endothelial cell-to-cell junctions: molecular organization and role in vascular homeostasis. Physiol Rev 2004, 84: 869-901

33. Begley DJ, Brightman MW: Structural and functional aspects of the blood-brain barrier. Prog Drug Res 2003, 61:39-78

34. Lee JY, Lee HE, Kang SR, Choi HY, Ryu JH, Yune TY: Fluoxetine inhibits transient global ischemia-induced hippocampal neuronal death and memory impairment by preventing blood-brain barrier disruption. Neuropharmacology 2014, 79:161-171

35. Bethea JR, Castro M, Keane RW, Lee TT, Dietrich WD, Yezierski RP: Traumatic spinal cord injury induces nuclear factorkappaB activation. J Neurosci 1998, 18:3251-3260

36. Xu J, Fan G, Chen S, Wu Y, Xu XM, Hsu CY: Methylprednisolone inhibition of TNF-alpha expression and NF-kB activation after spinal cord injury in rats. Brain Res Mol Brain Res 1998, 59:135-142

37. Yu Y, Chiba Y, Sakai H, Misawa M: Possible involvements of nuclear factor-kappa B and activator protein-1 in the tumor necrosis factor-alpha-induced upregulation of matrix metalloproteinase-12 in human alveolar epithelial A549 cell line. J Pharmacol Sci 2010, 112: $83-88$

38. Suzuki Y, Nagai N, Yamakawa K, Kawakami J, Lijnen HR, Umemura K: Tissue-type plasminogen activator (t-PA) induces stromelysin-1 (MMP-3) in endothelial cells through activation of lipoprotein receptor-related protein. Blood 2009, 114:3352-3358

39. Zhao X, Zmijewski JW, Lorne E, Liu G, Park YJ, Tsuruta Y, Abraham E: Activation of AMPK attenuates neutrophil proinflammatory activity and decreases the severity of acute lung injury. Am J Physiol Lung Cell Mol Physiol 2008, 295: L497-L504

40. Rosenberg GA, Cunningham LA, Wallace J, Alexander S, Estrada EY, Grossetete M, Razhagi A, Miller K, Gearing A: Immunohistochemistry of matrix metalloproteinases in reperfusion injury to rat brain: activation of MMP-9 linked to stromelysin-1 and microglia in cell cultures. Brain Res 2001, 893:104-112

41. Ramos-DeSimone N, Hahn-Dantona E, Sipley J, Nagase H, French DL, Quigley JP: Activation of matrix metalloproteinase-9 (MMP-9) via a converging plasmin/stromelysin-1 cascade enhances tumor cell invasion. J Biol Chem 1999, 274:13066-13076

42. Garbuzova-Davis S, Saporta S, Haller E, Kolomey I, Bennett SP, Potter H, Sanberg PR: Evidence of compromised blood-spinal cord barrier in early and late symptomatic SOD1 mice modeling ALS. PLoS One 2007, 2:e1205

43. Wolburg H, Lippoldt A: Tight junctions of the blood-brain barrier: development, composition and regulation. Vascul Pharmacol 2002, 38:323-337

44. Liebner S, Kniesel U, Kalbacher H, Wolburg H: Correlation of tight junction morphology with the expression of tight junction proteins in blood-brain barrier endothelial cells. Eur J Cell Biol 2000, 79: 707-717

45. Date Y, Kojima M, Hosoda H, Sawaguchi A, Mondal MS, Suganuma T, Matsukura S, Kangawa K, Nakazato M: Ghrelin, a novel growth hormone-releasing acylated peptide, is synthesized in a distinct endocrine cell type in the gastrointestinal tracts of rats and humans. Endocrinology 2000, 141:4255-4261

46. Asahi M, Wang X, Mori T, Sumii T, Jung JC, Moskowitz MA, Fini ME, Lo EH: Effects of matrix metalloproteinase-9 gene knock-out on the proteolysis of blood-brain barrier and white matter components after cerebral ischemia. J Neurosci 2001, 21: $7724-7732$

47. Yang Y, Estrada EY, Thompson JF, Liu W, Rosenberg GA: Matrix metalloproteinase-mediated disruption of tight junction proteins in cerebral vessels is reversed by synthetic matrix metalloproteinase inhibitor in focal ischemia in rat. J Cereb Blood Flow Metab 2007, 27:697-709

48. Yang Y, Thompson JF, Taheri S, Salayandia VM, McAvoy TA, Hill JW, Yang Y, Estrada EY, Rosenberg GA: Early inhibition of MMP activity in ischemic rat brain promotes expression of tight junction proteins and angiogenesis during recovery. J Cereb Blood Flow Metab 2013, 33:1104-1114

49. Yeh CH, Lin YM, Wu YC, Lin PJ: Inhibition of NF-kappa B activation can attenuate ischemia/reperfusion-induced contractility impairment via decreasing cardiomyocytic proinflammatory gene upregulation and matrix metalloproteinase expression. J Cardiovasc Pharmacol 2005, 45:301-309

50. Beattie MS, Farooqui AA, Bresnahan JC: Review of current evidence for apoptosis after spinal cord injury. J Neurotrauma 2000, 17: 915-925

51. Popovich PG, van RN, Hickey WF, Preidis G, McGaughy V: Hematogenous macrophages express CD8 and distribute to regions of lesion cavitation after spinal cord injury. Exp Neurol 2003, 182: $275-287$

52. Okada S, Nakamura M, Mikami Y, Shimazaki T, Mihara M, Ohsugi Y, Iwamoto Y, Yoshizaki K, Kishimoto T, Toyama Y, Okano H: Blockade of interleukin-6 receptor suppresses reactive astrogliosis and ameliorates functional recovery in experimental spinal cord injury. J Neurosci Res 2004, 76:265-276

53. Carlson SL, Parrish ME, Springer JE, Doty K, Dossett L: Acute inflammatory response in spinal cord following impact injury. Exp Neurol 1998, 151:77-88

54. Hamada Y, Ikata T, Katoh S, Nakauchi K, Niwa M, Kawai Y, Fukuzawa K: Involvement of an intercellular adhesion molecule 1dependent pathway in the pathogenesis of secondary changes after spinal cord injury in rats. J Neurochem 1996, 66:1525-1531

55. Taoka Y, Okajima K, Uchiba M, Murakami K, Kushimoto S, Johno M, Naruo M, Okabe H, Takatsuki K: Role of neutrophils in spinal cord injury in the rat. Neuroscience 1997, 79:1177-1182

56. Saiwai H, Ohkawa Y, Yamada H, Kumamaru H, Harada A, Okano H, Yokomizo T, Iwamoto Y, Okada S: The LTB4-BLT1 axis mediates neutrophil infiltration and secondary injury in experimental spinal cord injury. Am J Pathol 2010, 176:2352-2366

57. Kim YS, Kim SS, Cho JJ, Choi DH, Hwang O, Shin DH, Chun HS, Beal MF, Joh TH: Matrix metalloproteinase-3: a novel signaling proteinase from apoptotic neuronal cells that activates microglia. J Neurosci 2005, 25:3701-3711

58. Kim YS, Choi DH, Block ML, Lorenzl S, Yang L, Kim YJ, Sugama S, Cho BP, Hwang O, Browne SE, Kim SY, Hong JS, Beal MF, Joh TH: A pivotal role of matrix metalloproteinase-3 activity in dopaminergic neuronal degeneration via microglial activation. FASEB J 2007, 21:179-187

59. Zhong Z, Deane R, Ali Z, Parisi M, Shapovalov Y, O'Banion MK, Stojanovic K, Sagare A, Boillee S, Cleveland DW, Zlokovic BV: ALS-causing SOD1 mutants generate vascular changes prior to motor neuron degeneration. Nat Neurosci 2008, 11:420-422

60. Zhong Z, Ilieva H, Hallagan L, Bell R, Singh I, Paquette N, Thiyagarajan M, Deane R, Fernandez JA, Lane S, Zlokovic AB, Liu T, Griffin JH, Chow N, Castellino FJ, Stojanovic K, Cleveland DW, Zlokovic BV: Activated protein C therapy slows ALS-like disease in mice by transcriptionally inhibiting SOD1 in 
motor neurons and microglia cells. J Clin Invest 2009, 119 3437-3449

61. Winkler EA, Sengillo JD, Sagare AP, Zhao Z, Ma Q, Zuniga E, Wang Y, Zhong Z, Sullivan JS, Griffin JH, Cleveland DW, Zlokovic BV: Blood-spinal cord barrier disruption contributes to early motor-neuron degeneration in ALS-model mice. Proc Natl Acad Sci U S A 2014, 111:E1035-E1042

62. Ogata Y, Itoh Y, Nagase H: Steps involved in activation of the promatrix metalloproteinase 9 (progelatinase B)-tissue inhibitor of metalloproteinases-1 complex by 4-aminophenylmercuric acetate and proteinases. J Biol Chem 1995, 270:18506-18511

63. MacPherson LJ, Bayburt EK, Capparelli MP, Carroll BJ, Goldstein R, Justice MR, Zhu L, Hu S, Melton RA, Fryer L, Goldberg RL, Doughty JR, Spirito S, Blancuzzi V, Wilson D, O'Byrne EM, Ganu V, Parker DT: Discovery of CGS 27023A, a non-peptidic, potent, and orally active stromelysin inhibitor that blocks cartilage degradation in rabbits. J Med Chem 1997, 40: $2525-2532$

64. Pauly T, Ratliff M, Pietrowski E, Neugebauer R, Schlicksupp A, Kirsch J, Kuhse J: Activity-dependent shedding of the NMDA receptor glycine binding site by matrix metalloproteinase 3: a PUTATIVE mechanism of postsynaptic plasticity. PLoS One 2008, 3:e2681
65. Bertini I, Calderone V, Fragai M, Luchinat C, Mangani S, Terni B: Crystal structure of the catalytic domain of human matrix metalloproteinase 10. J Mol Biol 2004, 336:707-716

66. Bertini I, Calderone V, Cosenza M, Fragai M, Lee YM, Luchinat C, Mangani S, Terni B, Turano P: Conformational variability of matrix metalloproteinases: beyond a single 3D structure. Proc Natl Acad Sci U S A 2005, 102:5334-5339

67. de CR Jr, Burns CL, McAdoo DJ, Romanic AM: Metalloproteinase increases in the injured rat spinal cord. Neuroreport 2000, 11:3551-3554

68. Kim JH, Kim JH, Yu YS, Kim DH, Kim KW: Recruitment of pericytes and astrocytes is closely related to the formation of tight junction in developing retinal vessels. J Neurosci Res 2009, 87:653-659

69. Armulik A, Genove G, Mae M, Nisancioglu MH, Wallgard E, Niaudet C, He L, Norlin J, Lindblom P, Strittmatter K, Johansson BR, Betsholtz C: Pericytes regulate the blood-brain barrier. Nature 2010, 468:557-561

70. Zozulya A, Weidenfeller C, Galla HJ: Pericyte-endothelial cell interaction increases MMP-9 secretion at the blood-brain barrier in vitro. Brain Res 2008, 1189:1-11

71. Bell RD, Winkler EA, Singh I, Sagare AP, Deane R, Wu Z, Holtzman DM, Betsholtz C, Armulik A, Sallstrom J, Berk BC, Zlokovic BV: Apolipoprotein E controls cerebrovascular integrity via cyclophilin A. Nature 2012, 485:512-516 